\title{
The MATS satellite mission - gravity wave studies by Mesospheric Airglow/Aerosol Tomography and Spectroscopy
}

\author{
Jörg Gumbel ${ }^{1}$, Linda Megner ${ }^{1}$, Ole Martin Christensen ${ }^{1,2}$, Nickolay Ivchenko ${ }^{3,4}$, Donal P. Murtagh ${ }^{2}$, \\ Seunghyuk Chang ${ }^{6}$, Joachim Dillner ${ }^{1}$, Terese Ekebrand ${ }^{7}$, Gabriel Giono ${ }^{3}$, Arvid Hammar ${ }^{5,7}$, Jonas Hedin ${ }^{1}$, \\ Bodil Karlsson ${ }^{1}$, Mikael Krus ${ }^{7}$, Anqi Li ${ }^{2}$, Steven McCallion ${ }^{7}$, Georgi Olentšenko ${ }^{3}$, Soojong Pak ${ }^{8}$, Woojin Park ${ }^{8}$, \\ Jordan Rouse $^{7}$, Jacek Stegman ${ }^{1}$, and Georg Witt ${ }^{1,+}$ \\ ${ }^{1}$ Department of Meteorology (MISU), Stockholm University, Stockholm, Sweden \\ ${ }^{2}$ Earth and Space Sciences, Chalmers University of Technology, Göteborg, Sweden \\ ${ }^{3}$ School of Electrical Engineering, Royal Institute of Technology (KTH), Stockholm, Sweden \\ ${ }^{4}$ South African National Space Agency, Hermanus 7200, South Africa \\ ${ }^{5}$ Department of Microtechnology and Nanoscience, Chalmers University of Technology, Göteborg, Sweden \\ ${ }^{6}$ Center for Integrated Smart Sensors, KAIST Dogok Campus, Seoul, Republic of Korea \\ ${ }^{7}$ Omnisys Instruments AB, August Barks gata 6B, Västra Frölunda, Sweden \\ ${ }^{8}$ School of Space Research, Kyung Hee University, Yongin-si, Republic of Korea \\ $\mathbf{t}_{\text {deceased }}$
}

Correspondence: Jörg Gumbel (gumbel@misu.su.se)

Received: 2 November 2018 - Discussion started: 17 December 2018

Revised: 9 July 2019 - Accepted: 6 August 2019 - Published: 13 January 2020

\begin{abstract}
Global three-dimensional data are a key to understanding gravity waves in the mesosphere and lower thermosphere. MATS (Mesospheric Airglow/Aerosol Tomography and Spectroscopy) is a new Swedish satellite mission that addresses this need. It applies space-borne limb imaging in combination with tomographic and spectroscopic analysis to obtain gravity wave data on relevant spatial scales. Primary measurement targets are $\mathrm{O}_{2}$ atmospheric band dayglow and nightglow in the near infrared, and sunlight scattered from noctilucent clouds in the ultraviolet. While tomography provides horizontally and vertically resolved data, spectroscopy allows analysis in terms of mesospheric temperature, composition, and cloud properties. Based on these dynamical tracers, MATS will produce a climatology on wave spectra during a 2-year mission. Major scientific objectives include a characterization of gravity waves and their interaction with larger-scale waves and mean flow in the mesosphere and lower thermosphere, as well as their relationship to dynamical conditions in the lower and upper atmosphere. MATS is currently being prepared to be ready for a launch in 2020 .
\end{abstract}

This paper provides an overview of scientific goals, measurement concepts, instruments, and analysis ideas.

\section{Introduction}

\subsection{Gravity waves in the mesosphere and lower thermosphere}

Atmospheric gravity waves are buoyancy waves that can transport momentum and energy over large distances in the atmosphere. Primary sources are disturbances in the troposphere such as flow over topography, convective systems, or jets. Conservation of energy causes the amplitude of the gravity waves to grow nearly exponentially as they propagate upward into less dense air at higher altitudes. As the waves break and dissipate, they deposit their momentum and energy into the background atmosphere. This in turn affects the atmosphere over a wide range of scales, from the local generation of turbulence to the forcing of a large scale circu- 
lation (Fritts and Alexander, 2003; Alexander et al., 2010). This dynamical forcing is most prominent in the mesosphere and lower thermosphere (MLT), at altitudes of typically 50$130 \mathrm{~km}$. Here a large fraction of upward-propagating gravity waves reach their maximum amplitudes and break. The resulting dynamical forcing causes a global-scale circulation in the mesosphere with strong upwelling in the summer polar region and downwelling in the winter polar region (Lindzen, 1981; Holton, 1982). Adiabatic cooling and heating connected to this circulation causes thermal conditions in the mesosphere to deviate far from radiative equilibrium. As one consequence, the polar summer mesosphere becomes the coldest place on Earth, with temperatures reaching well below $130 \mathrm{~K}$ despite permanently sunlit conditions. This makes the region the home of the highest clouds on Earth, noctilucent clouds (NLCs) (Thomas, 1991; Karlsson and Shepherd, 2018).

The role of gravity waves is further complicated as they interact with the background flow as they propagate through the middle atmosphere. This leads to an altitude-dependent filtering of the gravity wave spectrum by the wind field (e.g. Fritts and Alexander, 2003), including the wind components from the planetary waves and tidal waves. The gravity wave spectrum reaching higher altitudes thus carries an imprint of the dynamics at lower altitudes. This leads to a number of interesting teleconnections that can link conditions in widely separated regions of the atmosphere. Examples include the control of the summer mesosphere by lower atmospheric conditions in terms of inter- and intra-hemispheric coupling (Becker et al., 2004; Karlsson et al., 2007, 2011; Körnich and Becker, 2010; Gumbel and Karlsson, 2011; Karlsson and Becker, 2016). Interactions between gravity waves and the mean flow can also give rise to a generation of secondary waves in the mesosphere. Gravity waves can generate planetary waves, either directly through zonally non-uniform dissipation (Holton, 1984), or indirectly through induced baroclinic instability in the vicinity of jets (Plumb, 1983; Sato and Nomoto, 2015). The breakdown of gravity waves generates secondary gravity waves that propagate both upward and downward. This happens through the creation of temporally and spatially localized momentum and energy fluxes, which in turn create strong local body forces and flow imbalances which then excite the secondary waves (Vadas et al., 2003; Fritts et al., 2006; Becker and Vadas, 2018).

While today the basic nature of the wave-driven circulation of the middle atmosphere is understood, important mechanisms and interactions remain to be quantified. Most notably, this concerns wave sources, wave dissipation, and the resulting forcing of the mean flow. A decisive quantity to be specified is the directional momentum flux, including its altitude dependence and its spectral distribution with regard to horizontal and vertical wavelengths. Today, many general circulation models can explicitly simulate gravity waves with longer horizontal and vertical wavelengths, while shorter sub-grid waves need to be parameterized, e.g. in terms of the "wave drag" that they exert on the mean flow (Alexander et al., 2010; Geller et al., 2013). Rather than accounting for the detailed underlying physics, these wave parameterizations are often used as a means of tuning the model to ensure realistic output, e.g. in terms of middle atmospheric wind fields or temperature fields. Recently, important steps have been taken towards creating self-consistent gravity-waveresolving general circulation models (H.-L. Liu et al., 2014; Watanabe et al., 2015; Becker and Vadas, 2018). Complementary to these developments, ray-tracing models are important tools for case studies of wave events and comparisons to specific observational datasets (e.g. Marks and Eckerman, 1995; Preusse et al., 2006; Kalisch et al., 2014). A goal of ongoing model developments is to explicitly describe the entire chain from the lower atmospheric source region, via the lower and middle atmospheric wave filtering, to the wave effects in the MLT. Only wave-resolved simulations can be expected to describe the physics of, for example, intermittent wave interactions, energy cascades, and turbulence generation (Becker, 2012).

Observational data are critical for supporting such model developments, in particular in the MLT, where gravity wave effects are most evident. Unfortunately, we are today lacking global observations of wave spectra arriving in the MLT, and even more so of the contribution of different parts of the wave spectra to momentum transfer. Such observations are not only desirable to constrain model results directly in the MLT. Rather, gravity wave observations in the MLT can serve as a benchmark for testing wave implementations throughout the lower and middle atmosphere: general circulation models need to correctly describe the chain of wave processes at all altitudes in order to correctly reproduce resulting gravity wave properties observed in the MLT. In addition to providing a relevant database of gravity wave spectra, MLT studies are also needed that allow for investigations of the three-dimensional structure of wave propagation. An important example is the refraction of gravity waves in the vicinity of the mesospheric jet (Sato et al., 2009; Preusse et al., 2009; Ern et al., 2011). Other three-dimensional propagation effects concern the interaction of gravity waves with the polar vortex (McLandress et al., 2012; de Wit et al., 2014; Wright et al., 2017) or the suggested refraction of gravity waves during sudden stratospheric warmings (Thurairajah et al., 2014; Ern et al., 2016).

A field of particular interest is the relationship between gravity waves and NLCs. As described above, the gravitywave-driven large-scale circulation is the very cause of the extremely cold polar summer mesopause region, and thus a pre-condition for the formation of NLCs. On more local scales, gravity-wave-induced variations of temperature and vertical wind strongly affect NLC conditions, and can both cause, enhance, or prohibit the formation of the clouds (e.g. Rapp et al., 2002; Kaifler et al., 2018). At the same time, ground-based and space-based observations of NLCs are a primary source of our knowledge about gravity wave activ- 
ity in the middle atmosphere (e.g. Witt, 1962; Chandran et al., 2009; Rong et al., 2018; Gumbel and Karlsson, 2011). Gravity waves may also play an important role in explaining other dynamical NLC features like so-called ice fronts or ice voids (Megner et al., 2018).

While the above descriptions have focused on gravity wave interactions with larger-scale waves and the mean flow from the lower atmosphere to the MLT, the importance of gravity waves extends well beyond these altitudes. The MLT can be regarded as a transition region where many fundamental changes occur in atmospheric properties. Examples are the transition from well-mixed, turbulent conditions to molecular diffusion, a transition to non-local thermodynamic equilibrium with a substantially increased lifetime of excited species, a transition to an extreme-UV radiative environment, or the transition to increasing importance of ionospheric processes. Various "layered phenomena" in the MLT can be regarded as manifestations of these transitions. Prominent phenomena include dayglow and nightglow; layers of metal, dust or ice; and various plasma processes - all demonstrating strong links to both below and above. Despite this fact, the altitude around $100 \mathrm{~km}$ has long been regarded as a dividing line between different research communities, separating the middle and upper atmosphere. This view has changed in recent decades and has today been replaced by a strong interest in "whole atmosphere" model approaches that emphasize the connecting rather than the dividing role of the MLT (e.g. Roble, 2000; Marsh et al., 2007; Akmaev, 2011). Wave processes play a central role in this respect, and in bridging the atmospheric communities.

In addition to comprehensive whole atmosphere modelling efforts, there has been growing observational evidence of thermospheric and ionospheric responses to wave processes in the lower and middle atmosphere. The dynamical morphology of thermosphere and ionosphere has been shown to be strongly connected to tidal waves (e.g. Anderson, 1981; Oberheide et al., 2009), but also to planetary waves (e.g. Chen, 1992; Forbes and Leveroni, 1992) and gravity waves (e.g. Röttger, 1977; Park et al., 2014; Forbes et al., 2016; Trinh et al., 2018; Vadas et al., 2019). A basic open question concerns the relative importance of primary, secondary, and higher-order gravity waves in propagating from the middle atmosphere to the thermosphere and ionosphere through a multi-step vertical coupling process (Becker and Vadas, 2018; Vadas and Becker, 2018, 2019). In the altitude range $100-300 \mathrm{~km}$, gravity waves have been shown to create temperature variations of $50 \mathrm{~K}$ and density variations of $10 \%-$ $25 \%$ over spatial scales of tens to hundreds of kilometres (Vadas and Liu, 2013). As the gravity waves interact with the background flow before reaching these altitudes, fingerprints of lower atmospheric sources and middle atmospheric circulation systems are transported well into the thermosphere and ionosphere (Siskind et al., 2012). A prominent example is dynamic coupling suggested to occur during sudden stratospheric warmings (Funke et al., 2010; Chau et al., 2011).
Akmaev (2011) estimates that more than half of the regular daily and seasonal variability in the thermosphere and ionosphere is forced from below. Akmaev further concludes that the availability of global data on MLT dynamics and variability is a limiting factor for future scientific progress, thus contrasting the MLT to the "data-rich" lower atmosphere and upper thermosphere.

In summary, there is substantial need for global observations of gravity waves in the mesosphere and lower thermosphere. These datasets are needed to support and verify ongoing developments of general circulation models, concerning both gravity wave parameterizations and gravitywave-resolved implementations. These datasets should provide (1) information about horizontal (and vertical) wave spectra in order to identify the dominant scales that govern interactions with the mean flow, larger-scale waves, and possibly secondary waves; (2) information about directional momentum flux as decisive quantity for these interactions; and (3) three-dimensional wave information in order to address detailed propagation and refraction effects in the vicinity relevant dynamical structures.

\subsection{Satellite measurements of gravity waves}

What is the current status regarding such global observations of gravity waves in the MLT? Several satellite missions have provided data on MLT structures that have been analysed in terms of wave activity on various scales. Most of these apply limb-viewing geometries in a number of spectral ranges. On the TIMED satellite, infrared limb measurements by the SABER instrument provide species and temperature distributions that allow for retrievals of gravity waves and planetary waves (Krebsbach and Preusse, 2007; Forbes et al., 2009; Preusse et al., 2009). The TIDI instrument provides MLT gravity wave data in terms of airglow Doppler wind measurements (Liu et al., 2009). On the ENVISAT satellite, infrared limb emission measurements by the MIPAS instrument cover the MLT and can provide large-scale wave structures that could also be traced into the thermosphere (Funke et al., 2010). From the SOFIE instrument on board the AIM satellite, gravity wave potential energy is inferred based on infrared solar occultation temperature retrievals throughout the stratosphere and mesosphere (X. Liu et al., 2014). Measurements by the SCIAMACHY instrument have been analysed in terms of MLT planetary wave structures in noctilucent clouds (von Savigny et al., 2007). On the Aura satellite, microwave limb measurements by the MLS instrument have provided mesospheric planetary wave data based on composition, temperature, and Doppler wind analysis (Limpasuvan et al., 2005; Wu et al., 2008). The above limb sounders can provide vertical retrieval resolutions down to a few kilometres. However, all gravity wave analysis from these limb measurements suffers from sparse horizontal sampling and the long line-of-sight integration, largely restricting the analysis 
to horizontal wavelengths exceeding several hundred kilometres.

Complementary to the above limb datasets, nadir-viewing satellite measurements have been analysed in terms of waves in the MLT, primarily focusing on horizontal wave structures. These studies employ observations of either noctilucent clouds or airglow layers. Basic wave parameters have been inferred from NLC observations by the UVIST instrument on board the MSX satellite (Carbary et al., 2000). On the AIM satellite, the CIPS instrument has provided comprehensive gravity wave information from near-nadir imaging of NLCs, resulting in wave climatologies covering horizontal wavelengths both above $100 \mathrm{~km}$ (Rusch et al., 2008; Chandran et al., 2009) and below $100 \mathrm{~km}$ (Rong et al., 2018). MLT gravity wave analysis based on nadir nightglow observations has been reported from the VIIRS instrument on board the NOAA/NASA Suomi satellite (Yue et al., 2014; Miller et al., 2015; Azeem et al., 2015), and the IMAP/VISI instrument on board the International Space Station (Perwitasari et al., 2016). All gravity wave analysis from these nadir imagers is largely restricted to information about horizontal wavelengths in the observed layer. For NLCs, however, information about vertical structures has recently been obtained by applying tomographic methods to the different viewing angles available from the AIM/CIPS observations (Hart et al., 2018).

For a more complete gravity wave analysis, threedimensional retrievals are desirable that provide spatial structures extending both shorter than $100 \mathrm{~km}$ in horizontal wavelength and shorter than $10 \mathrm{~km}$ in vertical wavelength (Preusse et al., 2008). Being limited by either limb or nadir geometry, we are so far lacking such three-dimensional gravity wave data in the MLT. In the stratosphere, techniques have been developed to overcome these limitations. The AIRS instrument on board the AQUA satellite measures upwelling radiation in a large number of spectral channels, and gravity waves have been retrieved from the upper troposphere to the mid-stratosphere (Hoffmann and Alexander, 2009; Gong et al., 2012). Additional techniques have been developed to maximize horizontal wave information from AIRS, utilizing either across-track nadir scans (Wright et al., 2017) or data from multiple satellite tracks (Ern et al., 2017). Enhanced horizontal information can also be obtained by combining data from several sounding instruments, like multiple GPS radio occultations (Wang and Alexander, 2010; Schmidt et al., 2016), or combined data from the HIRDLS instrument on board the Aura satellite and radio occultations (Alexander, 2015).

The ultimate way to obtain three-dimensional information about gravity waves is to apply tomographic techniques. Tomographic retrievals have been applied to the limb-scanning instruments MIPAS on board ENVISAT (Carlotti et al., 2001; Steck et al., 2005) and MLS on board Aura (Livesey et al., 2006). In the mesosphere, tomographic retrieval has been applied to the limb-scanning Odin satellite to study NLCs by the OSIRIS optical spectrograph (Hultgren et al., 2013; Hultgren and Gumbel, 2014), and water vapour and temperature by the SMR microwave instrument (Christensen et al., 2015, 2016). For instruments specifically designed for tomography, limb imaging is preferable over the above limb-scanning techniques. In this way, the number of lines of sight through a given atmospheric volume can be maximized. This has been utilized by the infrared limb imager of the OSIRIS instrument on board Odin (Degenstein et al., 2003, 2004), and by the airborne GLORIA instrument (Ungermann et al., 2011; Kaufmann et al., 2015). Limb imaging also provides the possibility to go from twodimensional to fully three-dimensional tomography. Ungermann et al. (2010) investigated requirements for gravity wave retrievals in the troposphere and stratosphere, emphasizing the need for a fully three-dimensional tomographic analysis. Krisch et al. (2018) discussed tomographic retrieval with special emphasis on the limited range of observation angles that are typically available from limb measurements.

In this paper, we describe a new satellite mission aiming at three-dimensional tomographic studies of gravity waves and other structures in the upper mesosphere and lower thermosphere. The MATS satellite will perform limb imaging of the $\mathrm{O}_{2}$ atmospheric band airglow in the near-infrared and of NLCs in the ultraviolet. In combination with the tomography, spectroscopic techniques will be applied to infer atmospheric temperature and composition from the $\mathrm{O}_{2}$ emissions, and microphysical cloud properties from the NLC measurements. A complementary camera will provide nadir imaging of structures in the $\mathrm{O}_{2}$ atmospheric band nightglow on smaller spatial scales. A similar mission with a focus on the $\mathrm{O}_{2}$ atmospheric band nightglow has recently been described by Song et al. (2017). As compared to the pure limb imaging by MATS, Song et al. (2017) envisage tomographic retrievals utilizing both limb and sub-limb viewing.

The next section describes the basic ideas of the MATS mission, with a focus on scientific objectives and resulting instrument requirements. Section 3 provides details about the instrument design. Section 4 introduces the retrieval ideas behind MATS and the basic data processing. Section 5 describes operational planning. Section 6 concludes with a summary and some perspectives towards scientific collaboration. Note that the idea of this paper is to provide a general overview over the mission. More comprehensive details about instruments, retrieval methods, and scientific analysis will be published in separate papers.

\section{The MATS satellite mission}

\subsection{Scientific objectives}

The primary goal of MATS is to determine the global distribution of gravity waves and other structures in the MLT over a wide range of spatial scales. Primary measurement 
targets are airglow in the $\mathrm{O}_{2}$ atmospheric band and sunlight scattered from NLCs. These emissions will be measured in the altitude range $75-110 \mathrm{~km}$ and are to be analysed in terms of wave structures with horizontal wavelengths from tens of kilometres to global scales, and vertical wavelengths from 1 to $20 \mathrm{~km}$. Over a period of 2 years, MATS will thus build up a geographical and seasonal climatology of wave activity in the MLT. This database will then be the starting point for scientific analysis in various directions. Relating back to the overview in Sect. 1, major scientific questions are as follows:

What gravity wave spectra are present in the MLT, and how are these related to tropospheric sources and circulation conditions in the lower and middle atmosphere? These questions are tightly connected to wave-wave interactions such as filtering by planetary wave activity and in situ generation of secondary waves.

To what extent does MLT wave activity affect processes in the thermosphere and ionosphere? As part of this objective, methods need to be developed that utilize the mapping of mesospheric wave activity as an input to studies of thermospheric variability.

How can explicit and parameterized implementations of gravity waves be improved in atmospheric models? This relates back to the quest to reduce large uncertainties in current descriptions of wave sources, wave propagation, and wave interactions.

While the MATS gravity wave climatology will be the starting point for addressing these questions, complementary input from other sources will be important. This includes in particular meteorological reanalysis data, ionospheric monitoring systems, and other dedicated missions that provide data beyond the altitude range of the MATS measurements.

As described above, NLCs are one of the measurement targets of MATS. Since the pioneering days of NLC research, these clouds have transformed from a basic research object to a valuable research tool when it comes to remote sensing of the state of the MLT. Nonetheless, beyond using NLCs as a convenient tracer for gravity wave studies, the MATS science objectives also include NLCs in their own right:

How are NLCs affected by gravity waves and other transient processes in the MLT? This concerns both the microphysics of ice particles and the resulting evolution of observable cloud structures.

\subsection{Measurement concepts}

The above scientific objectives define the requirements on the measurements that MATS will perform. Tomography is the basis for obtaining three-dimensional information on spatial scales that are relevant for gravity wave studies. The tomographic retrieval needs input in terms of multiple line-ofsight observations through a given atmospheric volume. This is achieved by a limb imager that observes the atmosphere along the Earth's tangent direction, with a field of view covering tangent altitudes between 75 and 110 , and $300 \mathrm{~km}$ across the track. Figure 1 illustrates the observation geometry. In order to tomographically retrieve gravity wave information in the MLT, we need to utilize atmospheric emissions that are both sufficiently bright and susceptible to gravity wave activity. In the case of MATS, we utilize airglow in the $\mathrm{O}_{2}$ atmospheric band and scattering of sunlight by NLCs. Both $\mathrm{O}_{2}$ atmospheric band airglow and NLCs feature horizontal and vertical structures that are a direct response to gravity wave activity. As an additional benefit, both phenomena allow for a deeper analysis by applying spectroscopic techniques.

On MATS, the $\mathrm{O}_{2}$ atmospheric band is measured using four spectral channels in the near infrared between 750 and $775 \mathrm{~nm}$ (see Table 4 for details). Measurements will be performed both during daytime (dayglow) and nighttime (nightglow). As a primary step, the tomographic analysis will convert measured limb radiances to volume emission rates. Combining the four channels, subsequent spectroscopic analysis will utilize the rotational structure of the $\mathrm{O}_{2}$ atmospheric band emission to infer temperature (Babcock and Herzberg, 1948; Sheese et al., 2010). At the same time, the total volume emission rate in the $\mathrm{O}_{2}$ atmospheric band can be analysed in terms of odd oxygen densities: the atmospheric band nightglow provides a direct measure of atomic oxygen density (McDade et al., 1986; Murtagh et al., 1990). The atmospheric band dayglow, on the other hand, provides information about ozone density (Evans et al., 1988; Mlynczak et al., 2001), which in turn is related to atomic oxygen through photochemical equilibrium. Gravity waves in the MLT can be inferred from these measurements by observing patterns in either airglow volume emission, odd oxygen, or temperature. Among these, analysing gravity waves in the temperature field is most beneficial as temperature is directly connected to the basic state of the atmosphere and as gravity wave momentum flux becomes accessible (Ern et al., 2004). To this end, temperature amplitudes as well as horizontal and vertical wavelengths need to be inferred from the measurements.

NLCs are measured by MATS using two spectral channels in the ultraviolet at 270 and $305 \mathrm{~nm}$. While imaging at one wavelength is sufficient for analysing global NLC variations and local NLC structures, the use of two wavelengths gives the additional benefit of accessing particle sizes and ice content. To this end, the observed spectral dependence of NLC signal is fitted in terms of an Ångström exponent and compared to numerical scattering simulations (von Savigny et al., 2005; Karlsson and Gumbel, 2005). For typical NLC particle sizes, observations in the ultraviolet are preferable as they push the scattering deeper into the Mie regime, thus maximizing the amount of information that can be inferred from spectral measurements. In addition, wavelengths below $310 \mathrm{~nm}$ are efficiently absorbed by the stratospheric ozone layer and are therefore chosen to avoid complications 


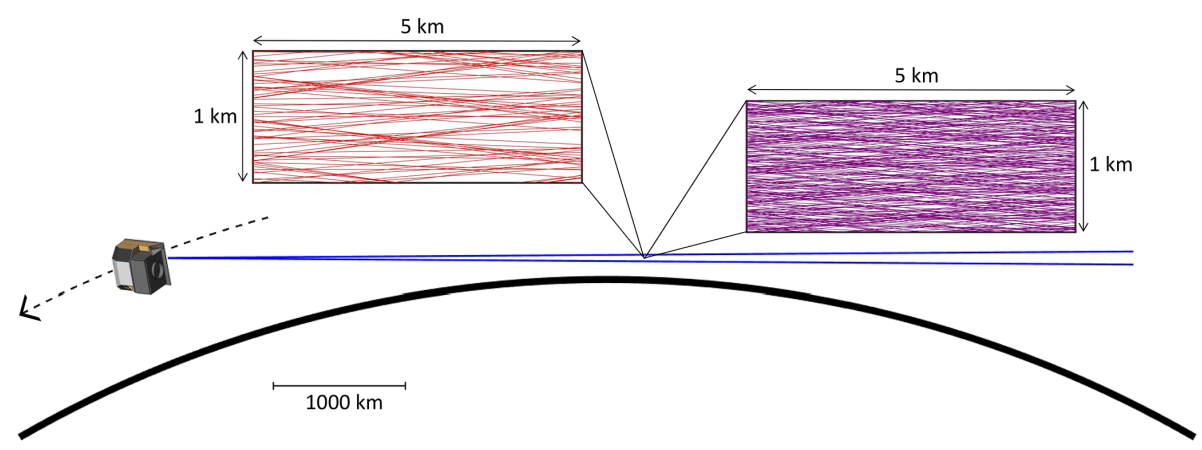

Figure 1. Illustration of the MATS limb observation geometry. From an orbit altitude of $585 \mathrm{~km}$, the vertical field of view of the limb instrument covers nominal tangent altitudes from 75 to $110 \mathrm{~km}$. The smaller inlays show examples of lines of sight filling a section of $5 \mathrm{~km} \times 1 \mathrm{~km}$ in the orbit plane. The red lines in the left inlay are representative for the density of lines of sight through a given measurement volume, taking into account the larger binned image pixel size and the longer readout interval in an $\mathrm{O}_{2}$ atmospheric band channel. The violet lines in the right inlay are representative for the density of lines of sight through a given measurement volume, taking into account the smaller binned image pixel size and the shorter readout interval in an NLC channel.

due to upwelling radiation. For MATS, the concrete wavelengths 270 and $305 \mathrm{~nm}$ are chosen both to ensure a sensitive retrieval in the NLC particle size range of interest (Sect. 4.6), and to minimize potential perturbations due to atmospheric emission features (airglow, aurora). The tomographic NLC data will be the basis for gravity wave analysis in terms of horizontal wavelengths. The vertical structure of the NLCs is strongly determined by the microphysics that governs cloud growth and sedimentation (Rapp and Thomas, 2006). The tomography will provide detailed insights into this vertical NLC evolution, including its possible modification by wave activity (Hultgren and Gumbel, 2014; Megner et al., 2016; Gao et al., 2018). However, since the vertical structure of the narrow NLC layers is dominated by microphysics rather than dynamical processes, a retrieval of vertical wavelengths of gravity waves will not be feasible from the NLC data.

The limb instrument will be described in Sect. 3, and details of the tomographic and spectral retrievals will be given in Sect. 4. Table 1 summarizes the above retrieval products from the MATS limb measurements. The table also states the required precision and spatial resolution of these retrieval products. These requirement are defined by the need to infer relevant gravity wave data from these retrieval products, in accordance with the overall objectives listed in the Sect. 2.1. Note that typical values are given for precision and resolution. These parameters depend on the altitude-dependent signal strengths. They are also adjustable as, for example, enhanced image binning can improve precision at the cost of resolution. These trade-offs will be further illustrated in the following sections.

In addition to these MATS limb measurements, an auxiliary nadir imager will take pictures of the $\mathrm{O}_{2}$ atmospheric band emission from below the satellite. This provides complementary information on smaller spatial scales down to 10 $20 \mathrm{~km}$ horizontal resolution, albeit restricted to a detection of structures rather than a detailed spectroscopic analysis. Dur- ing sunlit (or moonlit) conditions, nadir measurements of airglow layers get drowned in background light from the lower atmosphere. Gravity wave data from the MATS nadir camera will therefore be restricted to moonless nights. The nearterminator orbit of MATS is not optimal for such nightglow studies as sufficiently dark measurement conditions will only be available during the winter season at mid-latitudes and high latitudes. From the ground, nightglow imaging is a standard technique for local measurements of gravity waves in the MLT (e.g. Taylor et al., 1997; Espy et al., 2004). An obvious advantage of satellite measurements is global coverage; however, this comes with the disadvantage of lacking temporal coverage at a given location. Also, nadir imaging from a moving satellite is subject to image smearing (motion blur), thus implying a restriction to short integration times and strong wave features.

\subsection{Mission development}

Original ideas for MATS date back longer than the current project development. A first mission concept was developed by Jacek Stegman and Donal Murtagh at Stockholm University in the 1990s, then under the name "Mesospheric Airglow Transient Signatures (MATS)". An important heritage for MATS is also the Odin satellite mission, both concerning satellite, instrument, and operational concepts (Murtagh et al., 2002; Llewellyn et al., 2004). For the Optical Spectrograph and InfraRed Imager System (OSIRIS) on board Odin, tomographic ideas were developed by Degenstein et al. (2003, 2004). In 2010, special "tomographic" scan modes were developed for Odin, covering a limited tangent altitude range of about $75-90 \mathrm{~km}$ with relatively high horizontal repetition rate. These measurements provided input to tomographic and spectroscopic retrievals (Hultgren and Gumbel, 2014) that served as important tests for the MATS mission development. 
Table 1. Products of the tomographic/spectroscopic retrievals from the MATS limb measurements. These serve as input to subsequent wave analysis.

\begin{tabular}{|c|c|c|c|c|c|}
\hline & \multicolumn{3}{|c|}{$\mathrm{O}_{2}$ atmospheric band dayglow/nightglow } & \multicolumn{2}{|c|}{ NLC } \\
\hline & $\begin{array}{l}\text { Emission } \\
\text { rates }\end{array}$ & Temperature & $\begin{array}{l}\mathrm{O} \text { and } \mathrm{O}_{3} \\
\text { abundance }\end{array}$ & $\begin{array}{l}\text { Brightness } \\
\text { (scattering } \\
\text { coefficient) }\end{array}$ & $\begin{array}{l}\text { Particle sizes } \\
\text { (̊̊ngström } \\
\text { exponent) }\end{array}$ \\
\hline Temporal coverage & all seasons & all seasons & all seasons & summer & summer \\
\hline Geographical coverage & global & global & global & poleward of $45^{\circ}$ & poleward of $45^{\circ}$ \\
\hline Altitudes & $75-110 \mathrm{~km}$ & $75-110 \mathrm{~km}$ & $75-110 \mathrm{~km}$ & $80-86 \mathrm{~km}$ & $80-86 \mathrm{~km}$ \\
\hline Precision & $1 \%-5 \%$ & $2-5 \mathrm{~K}$ (day), 5-20 K (night) & $1 \%-5 \%$ & $2 \%-5 \%$ & 0.25 \\
\hline $\begin{array}{l}\text { Retrieval resolution }(\mathrm{km}) \\
(\text { along track } \times \text { across } \\
\text { track } \times \text { vertical) }\end{array}$ & $60 \times 20 \times 1$ & $60 \times 20 \times 1 \mathrm{~km}$ & $60 \times 20 \times 1$ & $60 \times 10 \times 0.5 \mathrm{~km}$ & $60 \times 10 \times 0.5$ \\
\hline
\end{tabular}

Table 2. Selected parameters of the InnoSat satellite platform in its baseline configuration.

\begin{tabular}{ll}
\hline Mass & $50 \mathrm{~kg}$ (incl. $20 \mathrm{~kg}$ payload) \\
\hline Size & $85 \mathrm{~cm} \times 70 \mathrm{~cm} \times 55 \mathrm{~cm}$ \\
\hline Power & $45 \mathrm{~W}$ on orbit average \\
\hline Data volume & $180 \mathrm{MB} \mathrm{d}^{-1}$ \\
\hline $\begin{array}{l}\text { Pointing accuracy (in } \\
\text { terms of limb altitude) }\end{array}$ & $\begin{array}{l}5 \mathrm{~km} \text { pointing error (target) } \\
0.5 \mathrm{~km} \text { knowledge error (reconstruction) }\end{array}$ \\
\hline Orbit & $\begin{array}{l}\text { sun-synchronous, near-terminator, } \\
\text { polar orbit }\end{array}$ \\
\hline Nominal lifetime & 2 years \\
\hline
\end{tabular}

The current MATS satellite mission was developed in response to a call by the Swedish National Space Agency concerning "Innovative low-cost research satellite missions". MATS was selected after going through an initial mission definition phase in 2014.

An important basis for MATS is the InnoSat satellite platform developed by OHB Sweden and ÅAC Microtec (Larsson et al., 2016). InnoSat has been designed as a "universal" microsatellite platform that can host a variety of different payloads for aeronomy or astronomy research in low-Earth orbit. MATS is the first scientific mission to use InnoSat. As a consequence, much of the development of platform and payload have been carried out in parallel. MATS has been designed to use the "baseline configuration" of InnoSat. Table 2 lists important parameters that define this configuration. All parameters in Table 2 constitute boundary conditions for the design and performance of MATS, as will be illuminated further in Sects. 3 and 4.

Behind the development of the MATS instruments and scientific mission is an Instrument Consortium comprising Stockholm University, Calmers University of Technology in
Göteborg, and the Royal Institute of Technology in Stockholm, in collaboration with Omnisys Instruments (Göteborg), Molflow (Göteborg), and Kyung Hee University (Republic of Korea). This is complemented by a Platform Consortium comprising OHB Sweden in Stockholm and $\AA \mathrm{AC}$ Microtec in Uppsala, the companies behind InnoSat. The MATS satellite is currently in preparation for a launch in 2020. The launch will take place in a piggyback configuration to an orbit at an altitude around $600 \mathrm{~km}$. The nominal time of the Equator passage is around 06:00 and 18:00 local time (LT), thus providing a "near-terminator" orbit.

\section{Instrument design}

\subsection{Overview}

The MATS payload comprises four optical instruments: the six-channel limb imager and the nadir camera measure mesospheric emissions, as introduced in the previous section. A pair of nadir-viewing photometers measures upwelling radiation from the Earth surface and lower atmosphere, in support of the limb instrument analysis. A star-tracking camera directed in the opposite direction of the limb imager ensures accurate pointing of the satellite. Figure 2 shows the overall configuration.

The sun-synchronous polar orbit with nominal Equator passage near 06:00 and 18:30 LT is beneficial for an efficient satellite design. It ensures that the satellite receives sunlight largely during the entire mission, and that a solar panel mounted at one side of the platform is sufficient to make use of this sunlight. In addition, instruments and electronics will be shaded behind the solar panels during the mission. As for the field of view, the satellite will nominally be oriented so that the limb instrument looks backwards along the orbit. This provides the necessary overlap between subsequent images as input to the tomography retrieval. 

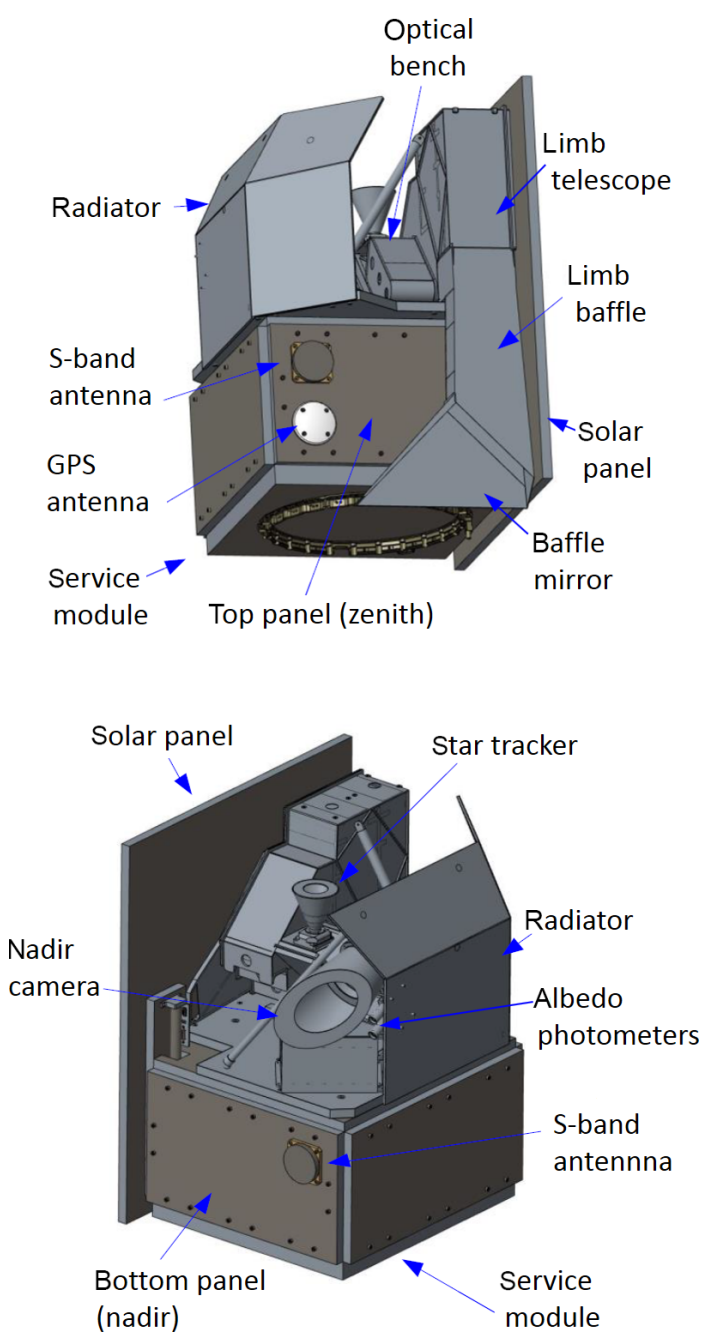

Figure 2. Layout of the MATS satellite.

\subsection{Limb instrument}

Since the goal is to investigate both NLCs and $\mathrm{O}_{2}$ atmospheric band emission, two separate wavelength regions will be measured by MATS. As described in Sect. 2.2, two UV channels will be used for the NLC study. To measure the atmospheric band emission, two main channels are used: a wideband channel covering the entire $0-0$ vibrational band, and a narrowband channel covering only the centre. In order to quantify the effect of background radiation and straylight on the atmospheric band measurements, a set of ancillary measurements are done using two background IR channels of the limb imager, as well as the pair of nadir-looking photometers that provide information about upwelling radiation both within and outside the atmospheric band. In order to achieve the MATS measurement objectives (Table 1), four basic tasks have been central to the limb instrument design: imaging quality, sensitivity (signal-to-noise ratio), spectral separation, and straylight suppression. Boundary conditions
Table 3. Overview of optical properties of the MATS limb telescope.

\begin{tabular}{ll}
\hline Type & $\begin{array}{l}\text { linear-astigmatism-free off-axis } \\
\text { three-mirror reflective }\end{array}$ \\
\hline Mirrors & $\begin{array}{l}\text { diamond turned aluminium with protective } \\
\text { UV coating, } 3 \mathrm{~nm} \mathrm{rms}\end{array}$ \\
\hline Field of view & $5.67^{\circ} \times 0.91^{\circ}(250 \mathrm{~km} \times 40 \mathrm{~km})$ \\
\hline Entrance pupil & $9.6 \mathrm{~cm}^{2}$ \\
\hline Focal length & $260 \mathrm{~mm}$ \\
\hline$f / D$ & 7.3 \\
\hline Aperture stop & located on the secondary mirror \\
\hline
\end{tabular}

for the design are defined by the InnoSat satellite platform in terms of mass, dimensions, power etc. (Table 2). Figure 3 shows the overall layout of the limb imager.

\subsubsection{Telescope}

The limb instrument is based on a single off-axis threemirror reflective telescope $(f / D=7.3)$ with a field of view of $5.67^{\circ} \times 0.91^{\circ}$ (Hammar et al., 2019). The mirrors are manufactured by Millpond ApS with fully free-form surfaces. They are made of aluminium with the active surfaces defined using diamond turning. The free-form design was optimized to achieve diffraction-limited imaging. Inter-mirror distances and angles were chosen to satisfy the linear-astigmatism-free condition. Linear astigmatism is the dominant aberration of off-axis reflecting telescopes and must be eliminated to obtain a wide field of view (Chang, 2015). A summary of properties of the limb telescope is found in Table 3.

\subsubsection{Splitter and filter network}

Following the telescope is a network of dichroic beam splitters and thin-film interference filters that are used to achieve the desired spectral selection. As the first element, a beamsplitter BS-UV-IR reflects wavelengths below $345 \mathrm{~nm}$ towards the UV part of the instruments, while longer wavelengths are transmitted towards the infrared part. Figure 4 shows the detailed distribution of spectral channels and optical elements. Each of the instrument's six channels uses a broadband filter to remove out-of-band signals, followed by a narrowband filter that ultimately defines the wavelengths transmitted to the image sensors. In addition, two folding mirrors are used to keep the optical components within the InnoSat platform envelope. Optical tests performed at breadboard and prototype level shows that the resolution requirement for the IR channels is fulfilled, while more careful mirror alignment is needed for the flight model to meet the imaging requirements of the UV channels. 

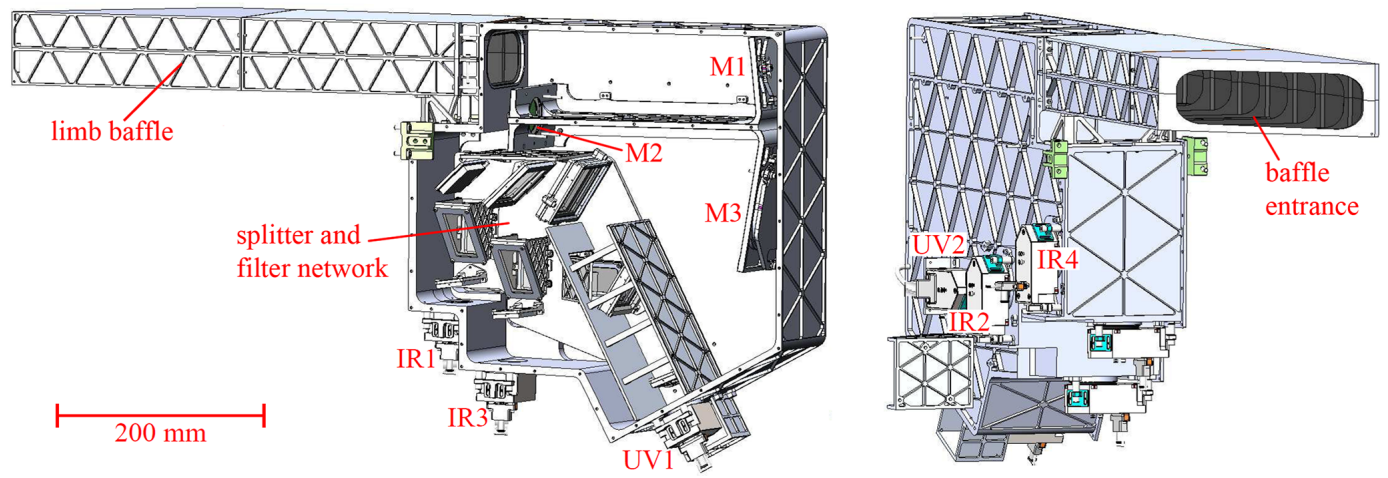

Figure 3. Overview of the MATS limb imager with one of the side covers removed (Hammar et al., 2018). Marked in the image are the telescope mirrors M1-M3, as well as the CCDs IR1-IR4 and UV1-UV2 for the six spectral channels.

(a)

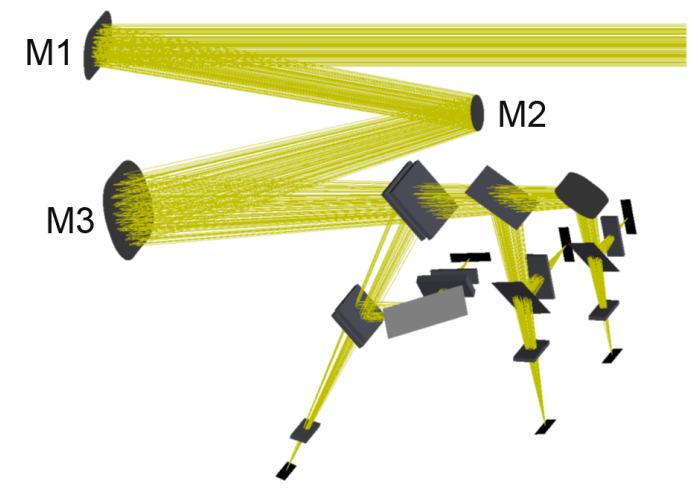

(b)

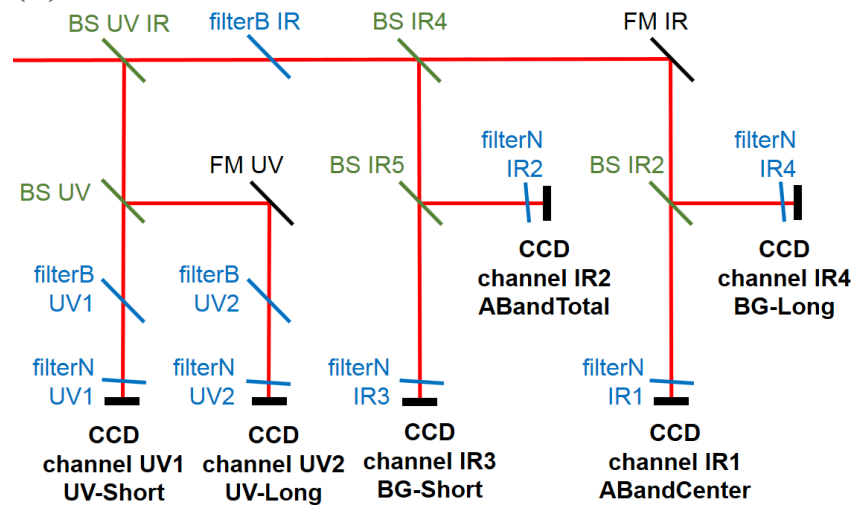

Figure 4. Overview of the optical paths in the limb imager. (a) Geometrical distribution of the optical elements, including the three telescope mirrors M1-M3. (b) Schematic of the channel layout with beamsplitters (BS), broad filters (filterB), narrow filters (filterN), folding mirrors (FM), and CCDs. See also Fig. 3.

\subsubsection{Baffle design}

One of the major design drivers for the limb instrument has been to minimize the impact of straylight from outside the field of view. This task is critical considering that the bright lower atmosphere is only $1-2^{\circ}$ below the nominal meso- spheric field of view. Central to the straylight handling is a long $(>650 \mathrm{~mm})$ baffle in front of the primary telescope mirror. To minimize the reflections inside the baffle, it is coated internally with Vantablack S-VIS, which has a reflectivity of less than $0.6 \%$ in the wavelength regions relevant for MATS. Furthermore, the limb housing and all mounting structures are coated using a black nickel (Hammar et al., 2018). During most of the mission, the baffle entrance will be in the shadow of the solar panel. However, during some high-latitude summer conditions, the Sun can illuminate satellite structures near the baffle. In order to minimize the risk of straylight entering the baffle, a plane mirror is placed in front of the baffle entrance (Fig. 2). As opposed to (black) surfaces that can scatter incident light in uncontrolled ways, this "baffle mirror" has been designed to reflect sunlight away from the instrument.

Since the MATS limb telescope lacks a field stop, Lyot stops are used in front of each image sensor. In addition, all sensors are deeply embedded in the structure. These measures ensure that the critical paths from the primary and secondary mirrors are removed. Furthermore, the inter-mirror distances were chosen to be as large as possible while still fitting into the available payload volume. By doing so, the subtended angles between the mirrors were minimized, which, in turn, minimizes the throughput of scattered light emanating from outside the nominal field of view.

To verify the performance of the stray-light suppression, a combination of experimental testing and modelling of the instrument in Zemax OpticStudio has been carried out (Hammar et al., 2018). From this, attenuations better than $10^{-5}$ are generally obtained for angles exceeding $1.5^{\circ}$, thus fulfilling the requirements for the mission.

\subsubsection{Readout electronics}

To record the incoming light, all channels use passively cooled back-lit CCD sensors (Teledyne E2V-CCD42-10). The data from each $C C D$ are read out by a CCD readout box (CRB) with an instrument on-board computer (OBC) to han- 


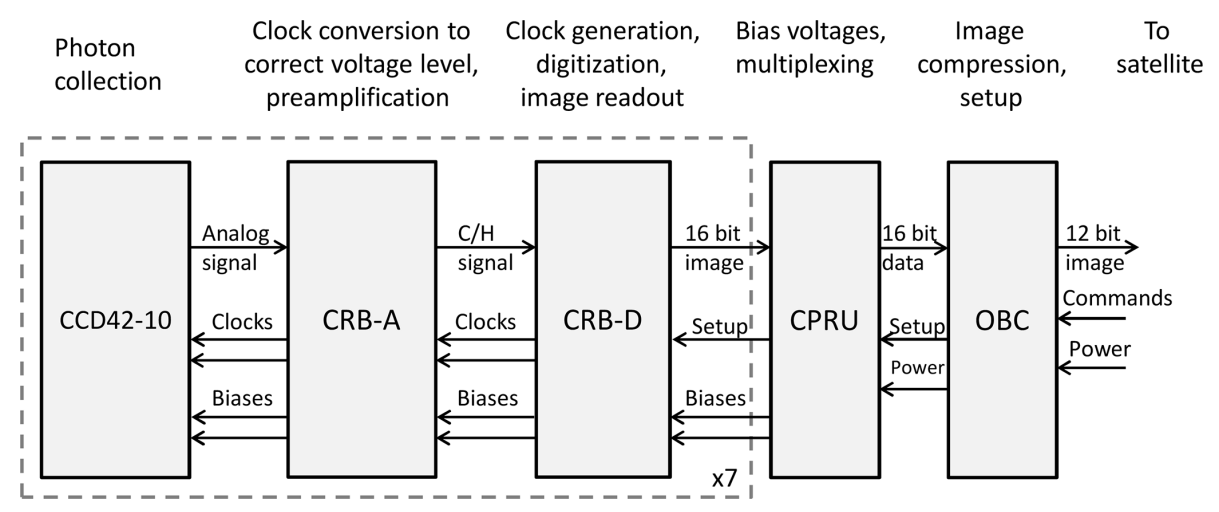

Figure 5. Overview of the MATS image acquisition. CCDs are controlled and read out by CCD Readout Boxes (CRB-A and CRB-D), connected to the CCD power regulation unit (CPRU) and on-board computer (OBC).

dle the data (Fig. 5). Two power and regulation units, located in the instrument electronics box together with the $\mathrm{OBC}$, provide adjustable voltages for CCD operation, and multiplex the control of the CRB settings and the data readout, for up to four imaging channels. The $\mathrm{OBC}$ then compresses the image (if applicable) before handing over to the Innosat platform which manages the satellite downlink. The nominal image format will be compressed 12 bit JPEG images, while a fullresolution uncompressed image readout is also available for in-flight calibration purposes.

The CCD provides $512 \times 2048$ image pixels. The field of view of each limb channel occupies a wide (along the limb) and short (in the vertical direction) area of interest. CCD readout implies a vertical shift of the image rows. To minimize the number of moving parts in the satellite no shutter is used in the instrument. As a consequence, the image rows continue to be exposed during the readout shifting, resulting in image smearing. The effect of this is minimized by a fast readout (using binning and skipping rows outside the region of interest) as well as correcting for smearing in postprocessing (Sect. 4.2).

To minimize noise and interference in the CCD readout, the readout electronics are composed of two parts, analog and digital. The analog box (CRB-A) is located in the immediate vicinity of the CCD. The function of CRB-A is to generate the necessary clock signals for the $\mathrm{CCD}$ and to provide signal conditioning for the CCD output signal. The clock signals are generated in the digital box (CRB-D, located together with the rest of the instrument electronics) with a standard logic voltage level, and are converted to the voltages needed by the CCD inputs by dedicated gate drivers. The signal from the CCD is pre-amplified and handled by a clamp and hold circuit. The amplified analog signal is passed over a differential connection to the CRB-D, where it is digitized by a 16 bit analog-to-digital converter (ADC) and stored in memory, available for transfer to the OBC. CRB-D uses a fieldprogrammable gate array for generating the multiple clocks for the $\mathrm{CCD}$, and sending the image to the OBC.
Since the different MATS channels and science modes have different requirements on the final image, the CRB firmware is flexible, allowing multiple settings of the readout to be changed, such as integration time, region of interest on the CCD, horizontal and vertical binning, or CCD output amplifier selection. An overview of the planned settings for the nominal science modes will be provided in Sect. 5 .

Exposure of the CCD to radiation in orbit will affect the dark current performance, which can be counteracted by adjusting the bias and clock voltages for the CCD in the power regulation unit. Hot pixels may develop on the CCD due to radiation. These can be excluded from binning, by flagging the columns that contain them as bad.

Giono et al. (2018) carried out performance measurements on a prototype version of the readout electronics, showing readout noise of about 50 electrons per CCD pixel using the high signal mode amplifier on the CCD. This can be further reduced to under 20 electrons per pixel by adjusting the preamplification gain and by using the low signal mode amplifier.

\subsection{Albedo photometers}

Each of the two albedo photometers consists of a two-lens telescope based on standard N-BK7 lenses, providing a field of view of $6^{\circ}$. In front of the telescope a pair of interference filters is placed on each photometer to discriminate against unwanted wavelengths. Baffles minimize straylight from outside the field of view. The detector is a Hamamatsu S1223-01 $\mathrm{Si}$ PIN photodiode. The system measures upcoming radiation at 759-767 and 752.5-755.5 $\mathrm{nm}$, corresponding to the limb imager channels IR2-ABand-total and IR3-BG-short, respectively (Table 4). The signal-to-noise ratio is better than 100 .

\subsection{Nadir camera}

The nadir camera is a Cooke triplet with an entrance pupil of $15 \mathrm{~mm}$, and an effective focal length of $50.6 \mathrm{~mm}$. Its field of view is $24.4^{\circ} \times 6.1^{\circ}$. From orbit, this covers an area of at 
Table 4. Overview of optical properties of the MATS limb and nadir channels. The image resolution of the channels is specified in two ways: imaging refers to the imaging quality of the optics in terms of the full width at half maximum of the point spread function, and binning refers to the size of the recorded image pixels after nominal binning on the CCD. Pixel sizes are given as vertical $\times$ horizontal for the limb channel, and as across track $\times$ along track (including motion blur) for the nadir channel.

\begin{tabular}{llllllc}
\hline Designation & $\begin{array}{l}\text { Central } \\
\text { wavelength }\end{array}$ & Bandwidth & $\begin{array}{l}\text { Tangent } \\
\text { altitudes }\end{array}$ & $\begin{array}{l}\text { Resolution } \\
\text { (imaging) }\end{array}$ & $\begin{array}{l}\text { Resolution } \\
\text { (binning) }\end{array}$ & $\begin{array}{c}\text { Signal-noise } \\
\text { ratio }\end{array}$ \\
\hline UV1-short & $270 \mathrm{~nm}$ & $3 \mathrm{~nm}$ & $70-90 \mathrm{~km}$ & $0.2 \mathrm{~km}$ & $0.2 \mathrm{~km} \times 5 \mathrm{~km}$ & 100 \\
UV2-long & $304.5 \mathrm{~nm}$ & $3 \mathrm{~nm}$ & $70-90 \mathrm{~km}$ & $0.2 \mathrm{~km}$ & $0.2 \mathrm{~km} \times 5 \mathrm{~km}$ & 100 \\
IR1-ABand-centre & $762 \mathrm{~nm}$ & $3.5 \mathrm{~nm}$ & $75-110 \mathrm{~km}$ & $0.4 \mathrm{~km}$ & $0.4 \mathrm{~km} \times 10 \mathrm{~km}$ & 500 \\
IR2-ABand-total & $763 \mathrm{~nm}$ & $8 \mathrm{~nm}$ & $75-110 \mathrm{~km}$ & $0.4 \mathrm{~km}$ & $0.4 \mathrm{~km} \times 10 \mathrm{~km}$ & 500 \\
IR3-BG-short & $754 \mathrm{~nm}$ & $3 \mathrm{~nm}$ & $75-110 \mathrm{~km}$ & $0.8 \mathrm{~km}$ & $0.8 \mathrm{~km} \times 50 \mathrm{~km}$ & 500 \\
IR4-BG-long & $772 \mathrm{~nm}$ & $3 \mathrm{~nm}$ & $75-110 \mathrm{~km}$ & $0.8 \mathrm{~km}$ & $0.8 \mathrm{~km} \times 50 \mathrm{~km}$ & 500 \\
NADIR & $762 \mathrm{~nm}$ & $8 \mathrm{~nm}$ & nadir & $10 \mathrm{~km}$ & $10 \mathrm{~km} \times 15 \mathrm{~km}$ & 100 \\
\hline
\end{tabular}

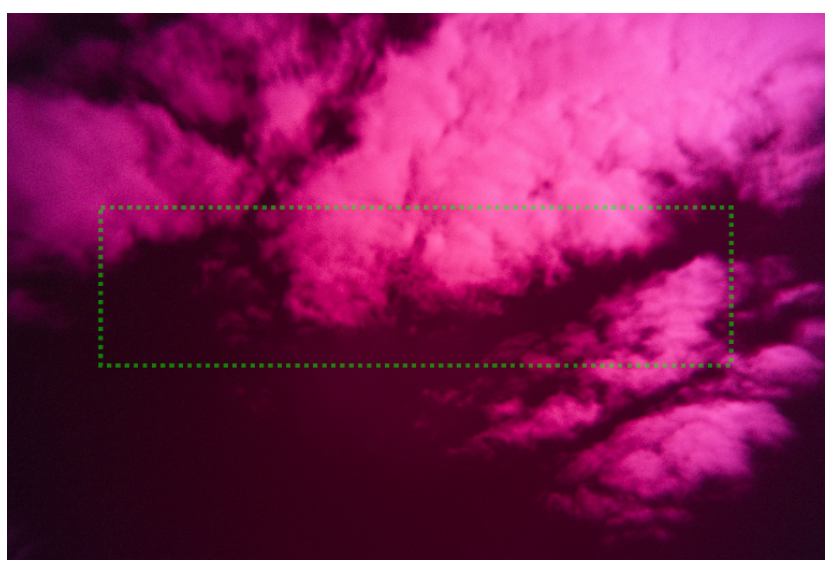

Figure 6. "First light" from a MATS instrument: ground-based photograph of a cloudy sky taken with the nadir objective mounted on a Canon camera house with a full frame sensor $(35 \mathrm{~mm})$. The dashed green rectangle denotes the cropped field of view as it will be seen with the MATS CCD sensor.

least $200 \mathrm{~km}$ across track and $50 \mathrm{~km}$ along track at $100 \mathrm{~km}$ altitude. The design can resolve $10 \times 10 \mathrm{~km}$ features at this altitude. Additional degradation occurs in the along-track direction due to smearing caused by the satellite movement during the exposure and readout phase. Figure 6 shows a sample image taken by a prototype nadir camera from the ground. In orbit, the nadir measurements aim at nighttime conditions, with the Sun located at least $10^{\circ}$ below the horizon for a groundbased observer. However, under these conditions the satellite will be fully illuminated by the Sun, and straylight handling is thus essential for the nadir camera. Similar to the limb instrument, in addition to being mounted in the shadow of the solar panel, efficient straylight suppression for the nadir camera is achieved by a baffle with black coating on the inside.

The readout of the nadir camera uses the same readout electronics as the limb instrument (Sect. 3.2.4), albeit operated in a different readout scheme. The satellite moves at a speed of about $7 \mathrm{~km} \mathrm{~s}^{-1}$, and in order to limit motion blur, nightglow images are taken with an exposure time no longer than $1 \mathrm{~s}$. Exposures are taken and the CCD is read out at a rate sufficient to obtain overlapping images along the groundtrack of the satellite. The result is a continuous nightglow image swath of width $200 \mathrm{~km}$ along the night part of the orbit.

\section{Data processing}

\subsection{Overview}

The data produced by the instruments on board MATS require several processing steps. The three major steps are as follows:

- Level 0 - geolocating the images and adding meta-data relevant for further processing.

- Level 1 - calibrating the images (and photometer measurements) such that the pixel values reflect the actual measured radiance.

- Level 2 - linking those values to the physical properties of the atmosphere via the 3-D tomographic reconstruction and spectroscopy.

Since the first step is mainly an administrative step for further processing, only the Level 1 and 2 processing will be discussed in this paper. Focus will be on the limb instrument as the main instrument on MATS. Figure 7 shows the overall processing chain for the limb data.

\subsection{Calibration of images}

After geolocation and time-tagging, each image from the limb channels must be calibrated such that the image displays the radiance falling on each binned image pixel on the CCD. To do this, a parameterized model of the instrument has been developed that takes into account transmissivity of the optics, dark current and quantum efficiency variations with temperature, readout smearing, and readout bias and gain variations 


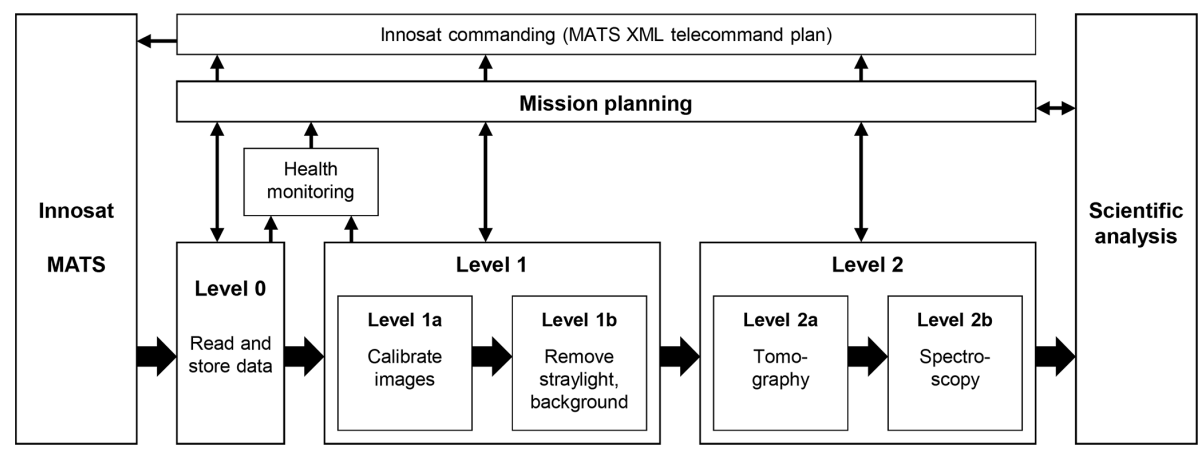

Figure 7. Overview of the data processing steps for the MATS limb imager.

in the readout electronics. Each of these effects behaves differently and must be measured and modelled separately. The parameters used in this modelling are a combination of preflight calibration measurements, and in-flight corrections to these parameters via special calibration modes (Sect. 5.2).

\subsubsection{Readout bias}

The bias produced by the readout electronics is determined for each image. This is done by means of blank pixel values, i.e. the signal from unexposed pixels in the readout register of the CCD. These pixels are shifted each time a row is read out, thus accumulating very little charge between consecutive rows. Two values, representing the average of the leading and trailing blank pixels, respectively, are recorded with each image as auxiliary information. Any inter-pixel variation in this offset will be compensated using a pixel-by-pixel map based on pre-flight calibration.

\subsubsection{Readout smearing}

In order to avoid risks associated with moving parts on the satellite, the CCDs have not been equipped with shutters. As a consequence, the CCD pixels are continuously illuminated, even during the image shifting associated with the readout, and are thus contaminated with signal from the "wrong" part of the image. To compensate for this effect, the image must be de-smeared by recursively correcting the pixel values in the CCD rows. While this process is completely deterministic for ideal noise-free measurements, it introduces minor image errors in the real data.

\subsubsection{Dark current}

The thermal energy of the CCD gives rise to electrons that are not due to incoming photons, but are nonetheless captured by the CCD's potential wells and counted as signal. The strong temperature dependence of this dark current is characterized pre-flight for the individual CCDs (Giorgi et al., 2018). Inflight measurements will monitor the detailed dark current properties of individual pixels throughout the mission.

\subsubsection{Radiometric correction}

The final step of the calibration involves estimating the amount of photons entering the telescope from the signal levels of the detected image. To do this, variations over the image of the optical throughout, inter-pixel variability in quantum efficiency, and variation in the gain of the readout electronics need to be accounted for. During preflight "flat field" calibrations, the telescope's optical throughput and the CCD's quantum efficiency will be determined together using measurements against a known radiance source. The readout gain (counts per electron) will be determined pre-flight at different temperatures. In orbit, the resulting radiative characteristics of the individual limb channels will be monitored using measurements of the moon, of stars (providing absolute calibration) and of molecular Rayleigh scattering from the Earth limb (providing relative inter-pixel variation).

\subsection{Straylight and background removal}

Before the limb radiances can be analysed in terms of airglow or NLCs, two unwanted contributions to the signal must be removed: background light originating from within the nominal field of view, and straylight originating from outside the nominal field of view. Background from inside the field of view comprises both unwanted emissions (airglow, aurora) and scattered light (in particular molecular Rayleigh scattering). Straylight from outside the field of view can reach the CCDs by scattering in the baffle, scattering from imperfect or dusty surfaces of the optical elements (in particular the primary telescope mirror), and/or scattering from structures inside the instrument housing. Although the design of the limb instrument is optimized for out-of-field rejection, some straylight signal is to be expected. To remove this signal, both amplitude and non-uniformity across each CCD need to be estimated. As described in the following subsections, the amplitude will be estimated by combining information from several channels and tangent altitudes. The non-uniformity will be parameterized based on the straylight modelling and testing carried out prior to launch (Hammar et al., 2018). 
The discrimination of unwanted and wanted radiances also needs to take account possible polarization effects. Based on pre-flight analysis, a potential source of polarization sensitivity of the MATS instrument are the beamsplitters mounted at $45^{\circ}$ to the incoming beam. Polarization properties of the individual instrument channels are measured pre-flight, and can partly also be inferred in orbit, based on measurements against polarized atmospheric Rayleigh scattering under varying role angles of the satellite. Once the instrument's polarization properties are determined, their effect on the limb measurements can be taken into account in the retrieval. However, as different contributions to the total signal (airglow, NLC scattering, molecular scattering, straylight) can be expected to feature different degrees of polarization, some assumptions are needed to handle polarization in the retrieval: in the UV, single scattering will be assumed both for the light scattering of the clouds and the background Rayleigh scattering. This is motivated by the efficient absorption of upwelling UV radiation from the lower atmosphere by the stratospheric ozone layer. In the IR, while unpolarized radiation can be assumed from the airglow emission, the background radiation is more complex. Analysis carried out with the SASKTRAN radiative transfer simulator (Bourassa et al., 2008) indicates that the degree of background polarization will vary from between 0.1 and 0.2 depending on the albedo of the lower atmosphere, which can be estimated from the data obtained by the albedo photometers on MATS.

In general, contributions of background light and straylight to the total signal can be difficult to distinguish from each other. This is in part due to the fact that both wanted and unwanted signals are expected to vary in similar ways along the orbit. Most notable, upwelling radiation, and thus local conditions at lower altitudes, will affect $\mathrm{O}_{2}$ atmospheric band dayglow, NLC scattering, molecular Rayleigh background, as well as straylight. In the MATS data processing, the procedures for removing background and straylight are therefore closely linked.

As for the removal of background and straylight from the $\mathrm{O}_{2}$ atmospheric band channels, the two IR background channels (Table 4) provide the starting point. The amplitude of the straylight is estimated from the signals seen in the IR background channels at the highest altitudes, where we expect negligible contribution from other sources of light. The background from the nominal field of view, on the other hand, is estimated using the full background channel images. This compensates not only for the Rayleigh background, but also for the possible presence of NLCs, and for other airglow and possibly auroral emission features. The total contribution of these signals cannot be estimated by simple linear interpolation between the two IR background channels. Rather, these signals show distinct spectral dependence (Sheese et al., 2010). In particular, since $\mathrm{O}_{2}$ resonantly absorbs upwelling radiation in the atmospheric band itself, both scattered background and straylight are weaker than what would be expected from linear interpolation between the two back- ground channels. To account for this, the lower atmospheric albedo needs to be quantified, regarding both absolute albedo and relative flux inside and outside the atmospheric band, which in turn depends on lower atmospheric cloudiness and cloud top height. This will be monitored by the pair of nadirlooking albedo photometers on board MATS that measure upwelling radiation inside and outside the atmospheric band. In combination with radiative transfer simulations of the relevant processes (Bourassa et al., 2008), this provides a more quantitative straylight and background correction, following the method described by Sheese et al. (2010).

As for the removal of background and straylight from the NLC channels, signals of concern are molecular Rayleigh background and straylight. Because of efficient absorption of UV radiation by stratospheric ozone, the major source for out-of-field straylight is Rayleigh scattering in the upper stratosphere, and the amount depends on the atmospheric ozone abundance and solar position. Similar to the IR, the amplitude of straylight will be estimated by assuming that the signal seen at the highest altitudes in the NLC images is completely dominated by straylight. As an option, Rayleigh background and the straylight will be removed only after the tomography has been completed. This is done to combine information from both spectral channels and from as many images as possible to estimate the Rayleigh scattering and straylight, which can be assumed to vary slowly in the horizontal direction. Atmospheric density profiles from an atmospheric model (NRLMSISE-00) will provide an initial estimate of the molecular Rayleigh background in the field of view. This estimate can then further be improved by normalizing it to the scattering observed under cloud-free conditions.

\subsection{Tomography}

Tomography will be applied on the images to reconstruct three-dimensional fields of atmospheric emission (or scattering). This will be done using an iterative maximum a posteriori (MAP) method (Rodgers, 2000). Here the 3-D field of emission is described by a state vector, $\boldsymbol{x}$, and the measured limb radiances by the measurement vector, $\boldsymbol{y}$. These vectors are related via a linear forward model:

$\boldsymbol{y}=\mathbf{K} \boldsymbol{x}$.

$\mathbf{K}$ is the Jacobian matrix and describes how emissions $\boldsymbol{x}$ from locations throughout the measurement volume contribute to radiances $\boldsymbol{y}$ from individual limb lines of sight. $\mathbf{K}$ thus contains the physics of the measurement, including observation geometry, radiative transfer, and instrument characteristics. For the MATS retrieval processing, $\mathbf{K}$ will be geometrically calculated on a grid using a spherical (rotating) Earth geometry. Absorption by ozone (in the UV channels) and selfabsorption (in the atmospheric band channels) will be included using a pre-existing climatology to calculate the optical depth along the path. 
Assuming that we have some a priori knowledge about the atmospheric emission described by the vector $\hat{\boldsymbol{x}}$ and a covariance matrix $\boldsymbol{S}_{\mathrm{a}}$, the maximum a posteriori state, $\boldsymbol{x}$, can be found using Bayesian estimation by solving the equation

$\hat{\boldsymbol{x}}=\left(\mathbf{K}^{\mathrm{T}} \mathbf{S}_{\mathrm{e}}^{-1} \mathbf{K}+\mathbf{S}_{\mathrm{a}}^{-1}\right)^{-1} \mathbf{K}^{\mathrm{T}} \mathbf{S}_{\mathrm{e}}^{-1}(\boldsymbol{y}-\mathbf{K} \boldsymbol{x})$,

where $\mathbf{S}_{\mathrm{e}}$ is the covariance matrix for the measurement vector $\boldsymbol{y}$.

For large scale problems, inverting Eq. (2) can become extremely memory-intensive to the point where a direct solver based on decomposition is no longer a possibility. Thus, the equation needs to be solved iteratively. Ungermann et al. (2010) have shown that this can be done efficiently by rewriting the equation above as

$$
\left(\mathbf{K}^{\mathrm{T}} \mathbf{S}_{\mathrm{e}}^{-1} \mathbf{K}+\mathbf{S}_{\mathrm{a}}^{-1}\right) \hat{\boldsymbol{x}}=\mathbf{K}^{\mathrm{T}} \mathbf{S}_{\mathrm{e}}^{-1}(\boldsymbol{y}-\mathbf{K} \boldsymbol{x})
$$

and solving it iteratively using the conjugate gradient method.

As Fig. 1 illustrates, the MATS observation geometry provides a large number of lines of sight through a given atmospheric volume. However, a challenge for the MATS tomographic retrieval is that lines of sight only span over a limited range of observation angles $\left(6^{\circ}\right)$, and that lines of sight cover very long paths (hundreds of kilometres) through an airglow layer or NLC layer. Tomographic retrievals under these conditions have been discussed by Krisch et al. (2018).

To illustrate the feasibility of the tomographic reconstruction, a prototype retrieval has been set up using a simple forward model with a pure spherical geometry (nonrotating Earth) and ignoring atmospheric absorption. A three-dimensional test field of NLC scattering coefficients is based on a combination of Odin/OSIRIS vertical profiles and AIM/CIPS images and covers a horizontal area of $5000 \mathrm{~km}$ along orbit and $\pm 175 \mathrm{~km}$ across the track (Fig. 8a). Forward model simulations and retrievals are performed on a set of measurements covering roughly $3000 \mathrm{~km}$ along the track (containing 167 limb images to be processed), $\pm 125 \mathrm{~km}$ on each side of the orbit plane, and altitudes from 60 to $100 \mathrm{~km}$. The resolution of the grid is $20 \times 6.4 \mathrm{~km} \times 0.5 \mathrm{~km}$ in the along-track, across-track, and vertical direction, respectively. Measurements are simulated with random noise added assuming shot-noise-limited performance with signal-to-noise ratios defined by the instrument specification. The measurement covariance matrix is set correspondingly (diagonal elements only). The retrievals are performed with very lax constraints using an a priori atmosphere equal to the background atmosphere and an a priori covariance matrix with only diagonal entries equal to $10^{-8} \mathrm{~m}^{-1} \mathrm{sr}^{-1}$.

The result from this retrieval test is shown in Fig. 8b. For the area fully covered by MATS measurements, i.e. $2000-3000 \mathrm{~km}$ along-track and $\pm 125 \mathrm{~km}$ across-track, the retrieval successfully reproduces the atmospheric field. For the area fully covered by the tomography, the mean square

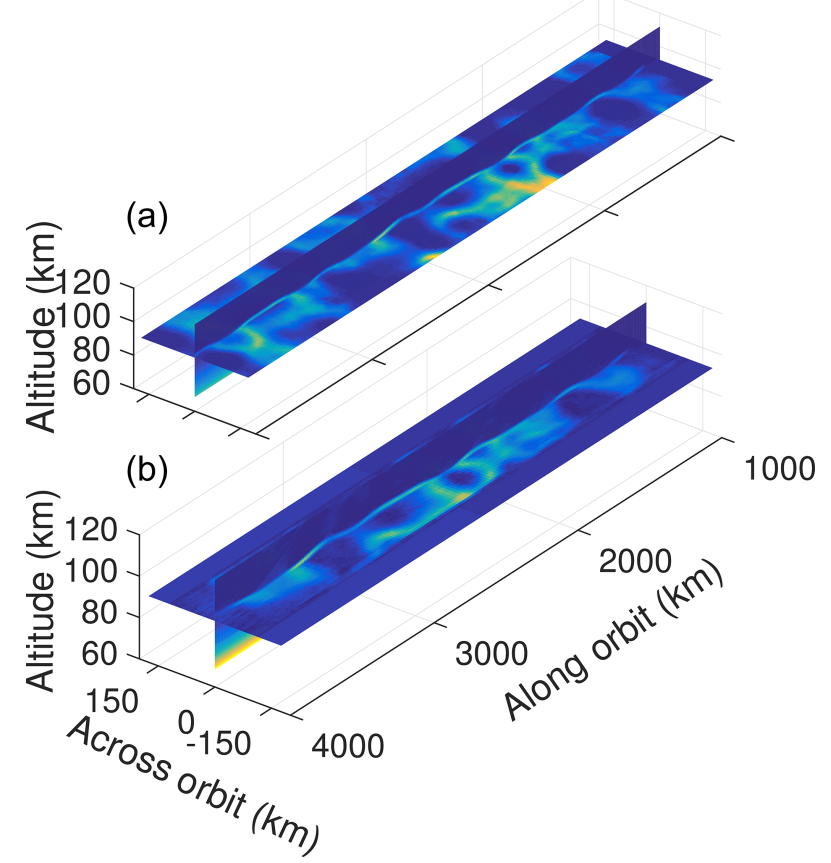

Figure 8. Example of tomographic retrieval simulations. Panel (a) shows the simulated "true" NLC volume scattering coefficient. Panel (b) shows the retrieved NLCs. Based on the simulated lines of sight, full retrieval is available in an area $2000-3000 \mathrm{~km}$ along orbit and $\pm 125 \mathrm{~km}$ across orbit.

error amounts to $1.5 \times 10^{-10} \mathrm{~m}^{-1} \mathrm{sr}^{-1}$, which corresponds to a relative error of $3 \%$ for a typical cloud brightness of $5 \times 10^{-9} \mathrm{~m}^{-1} \mathrm{sr}^{-1}$. As expected, some degradation can be seen on the edges due to limited tomographic information, with no information at the outermost regions where no measurement data are available. Along the track these effects will be mitigated by performing the retrieval on subsequently overlapping volumes along the orbit.

\section{5 $\mathrm{O}_{2}$ atmospheric band spectroscopy}

Following the tomographic retrieval of volume emission rates, the $\mathrm{O}_{2}$ atmospheric band is analysed to reveal temperature and oxygen densities. Starting point for the temperature retrieval is the ratio, $R$, of the signals in the two atmospheric band channels. Figure 9 shows the (re-)distribution of the rotational transitions in the $0-0$ vibrational band as a function of temperature. With a lifetime of $12 \mathrm{~s}$, the rotational distribution of $\mathrm{O}_{2}\left(b^{1} \Sigma\right)$ is in thermodynamic equilibrium up to altitudes around $120 \mathrm{~km}$, and thus representative for atmospheric temperature. The filter curves of the two MATS atmospheric band channels ("total" and "centre") have been chosen so that the ratio $R$ provides maximum sensitivity to temperature in the temperature range of interest.

Using Gaussian error estimation and assuming the error from each channel is roughly equal, the random error in the 


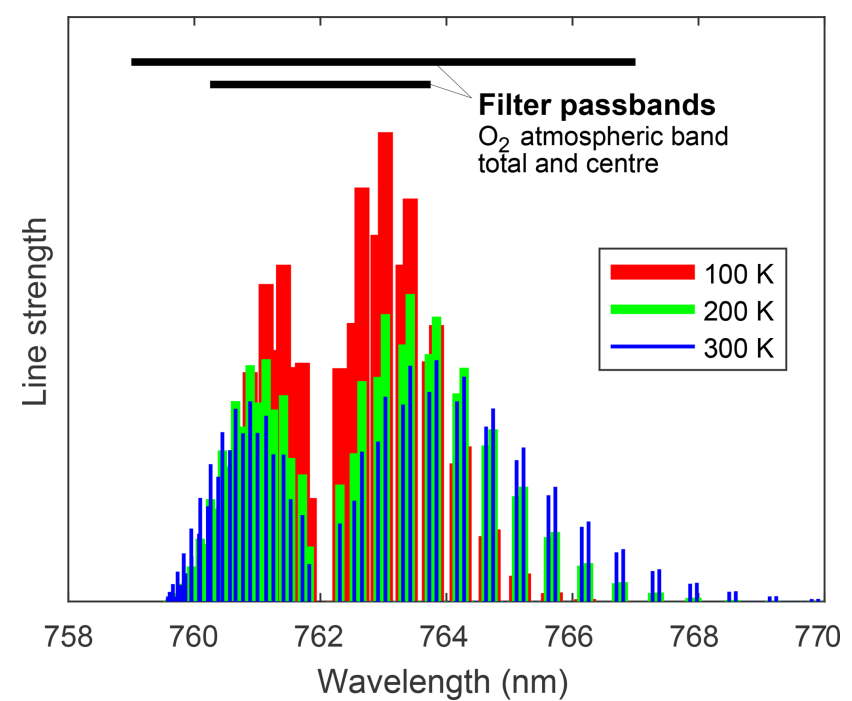

Figure 9. Spectral distribution of the $\mathrm{O}_{2}$ atmospheric band rotational transitions in the $0-0$ vibrational band as a function of temperature. The filter passbands of the limb instrument's atmospheric band channels cover the total band and its central part, respectively.

retrieved temperature is

$\Delta T=\sqrt{2} \frac{\Delta \epsilon}{\epsilon} \frac{\mathrm{d} T}{\mathrm{~d} R}$,

where $\epsilon$ and $\Delta \epsilon$ are the retrieved volume emission and its RMS error, and $\mathrm{d} T / \mathrm{d} R$ is the sensitivity of the temperature to the ratio between the signals in the two channels. In order to achieve a temperature precision of $2 \mathrm{~K}$, a signal-to-noise ratio $\epsilon / \Delta \epsilon$ better than 500 is needed, with can typically be achieved between 90 and $100 \mathrm{~km}$ altitude during daytime. It should be noted that the RMS error depends not only on the instrument, but also the covariance matrices used in the retrieval. The tomographic retrieval will apply horizontal and vertical regularization to suppress noise in the retrieved field. Hence, based on the true performance of the MATS instrument, further trade-off studies will be made between noise and spatial resolution in terms of measurement integration times, pixel binning, and regularization.

As stated in Table 1, possibilities to spectroscopically retrieve temperature from the $\mathrm{O}_{2}$ atmospheric band nightglow are more limited. When providing temperature data with the maximum tomographic resolution of $60 \mathrm{~km} \times 20 \mathrm{~km} \times 1 \mathrm{~km}$, the precision at nighttime will be 5-20 K. Again, the temperature precision can be improved by spatial or temporal averaging, at the cost of reduced spatial resolution of the tomographic output. However this trade-off is handled, possibilities to retrieve gravity wave data from the temperature field are rather limited during nighttime. Notwithstanding this limitation of the temperature analysis, nighttime gravity wave data can be obtained directly from the tomographically retrieved spatial distribution of nightglow volume emission rates.
The total volume emission rate of the atmospheric band provides direct information about the concentration of excited molecular oxygen $\mathrm{O}_{2}\left(b^{1} \Sigma\right)$. This is also the basis for retrieving concentrations of ozone and atomic oxygen, which are intimately linked to $\mathrm{O}_{2}\left(b^{1} \Sigma\right)$ via dayglow photochemical reactions (Evans et al., 1988). As compared to the more complex daytime retrievals, the atmospheric band nightglow emission is largely only dependent on atomic oxygen, which allows for rather direct retrieval of atomic oxygen concentrations (Sheese et al., 2011).

\subsection{NLC spectroscopy}

The tomographic retrievals from the MATS UV channels provide the amount of scattered sunlight by NLCs throughout the 3-D retrieval grid. Additional NLC information will be available from the atmospheric band background channels, thus providing complementary spectral NLC data in the infrared. The ratio of NLC-scattered sunlight to solar irradiance provides the volume scattering coefficient $\beta$ in each retrieval pixel.

The amount of light scattered from ice particles depends largely on the ratio between the size of the particle and wavelength of the light. Rayleigh scattering applies to particles much smaller that the wavelength, with the scattering coefficient approximately proportional to $\lambda^{-4}$. (Note that even in the Rayleigh limit the exponent is not exactly 4 , as spectral dependence of the ice particles' index of refraction causes an additional wavelength dependence.) For larger particles, interactions with the incoming sunlight get more complicated, and the scattering can be described as Mie scattering for spherical particles, or more complex numerical schemes for non-spherical particles (e.g. Mishchenko and Travis, 1998). Even in these more general cases, the wavelength dependence of the scattering in a limited spectral range can conveniently be described by a dependence $\lambda^{-\alpha}$, where $\lambda$ is the wavelength, and $\alpha$ a size-dependent exponent, the socalled Ångström exponent (e.g. von Savigny et al., 2005). This Ångström description is frequently used in particle size retrievals, relating spectral measurements of particle scattering to theoretical descriptions of scattering as a function of particle size. For the two UV channels of the MATS limb instrument, the Ångström exponent is obtained as

$\alpha=\frac{\log \left(\lambda_{2}\right)-\log \left(\lambda_{1}\right)}{\log \left(\beta_{1}\right)-\log \left(\beta_{2}\right)}$.

Once the Angström exponent in each tomographic retrieval pixel is determined, this value can be compared to scattering simulations of different ice particle distributions. Figure 11 shows an example of a lookup table connecting particle sizes and Ångström exponent for the MATS UV wavelengths. It is important to note, however, that the information that can be retrieved about the NLC particle population is limited: the Ångström exponent provides a single piece of information and can thus determine one parameter describing the size dis- 


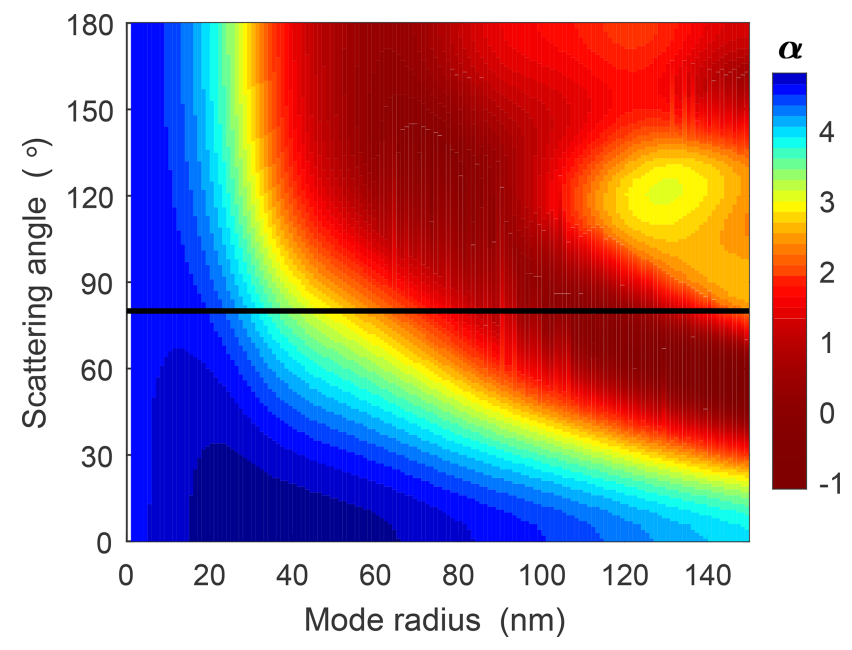

Figure 10. A lookup table for the NLC particle size analysis, generated from T-matrix simulations. Shown is the Ångström exponent as a function of mode radius and scattering angle. The black line indicates a typical scattering angle for MATS NLC observations.

tribution, e.g. a mode radius. This makes it necessary to make assumptions about additional parameters describing the particle population. Here we use the same assumptions that have been used in earlier retrieval studies, e.g. for the AIM/CIPS or Odin/OSIRIS instrument. This includes oblate spheroid ice particles with an axial ratio of 2 , and a normal distribution of particle sizes with a distribution width that varies with the mode radius (Lumpe et al., 2013; Hultgren and Gumbel, 2014). As Fig. 10 shows, the resulting relationship between Ångström coefficient and particle sizes will generally be ambiguous for larger mode radii exceeding about $100 \mathrm{~nm}$. A method to remove this ambiguity is to involve information from the infrared channels in the retrieval (Karlsson and Gumbel, 2005). Physically, NLC particle populations are expected to have mode radii below $100 \mathrm{~nm}$. Once particle size information has been inferred in the form of a mode radius, absolute scattering coefficient and size information can be combined to also retrieve the local ice content (ice mass density) of the cloud.

Through Gaussian error propagation the error in the Ångström parameter in a retrieval pixel can be estimated through

$\Delta \alpha=\frac{\sqrt{2}}{\log \left(\lambda_{1}\right)-\log \left(\lambda_{2}\right)} \frac{\Delta \beta}{\beta}$,

where $\Delta \beta$ is the uncertainty of the retrieved volume scattering coefficient, assuming it is roughly equal for the two wavelengths. From this, the error in the mode radius and ice mass density can be estimated through scattering simulations. In order to achieve a precision of 0.25 in the Ångström exponent, a signal-to-noise ratio $\beta / \Delta \beta$ better than 50 is needed.
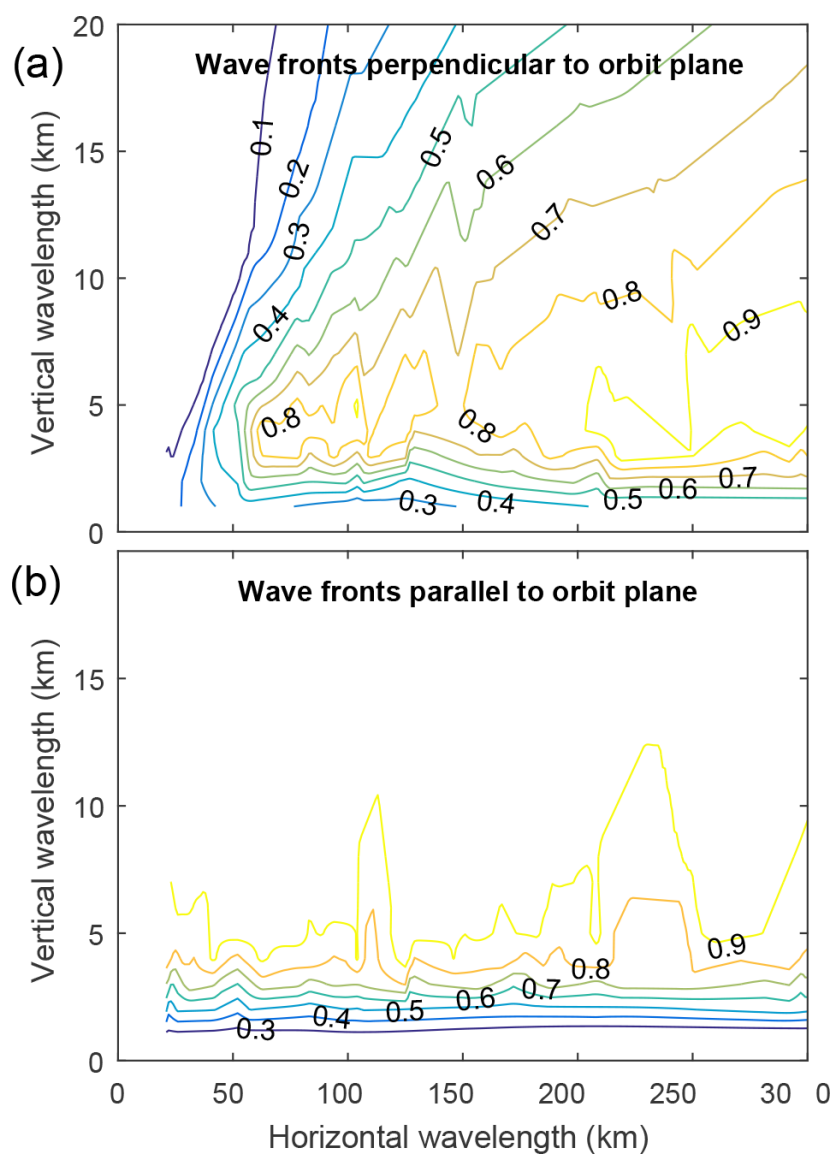

Figure 11. Simulated sensitivity of the MATS instrument to gravity waves of varying horizontal and vertical wavelengths. The sensitivity is defined as the ratio between the amplitude of the retrieved wave and the amplitude of the true wave field. Results are shown for waves with wave fronts perpendicular to the orbit plane (a) and parallel to the orbit plane (b).

\subsection{Retrieval of gravity waves}

As described in the previous sections, tomographic and spectroscopic analysis will provide three-dimensional fields of airglow emission rate, temperature, oxygen species, and NLC properties. These primary data products have been summarized in Table 1. All of these data fields can serve as input to an analysis of gravity waves and other atmospheric structures. However, there is a particular interest in wave retrievals from the temperature field as it allows for the analysis in terms gravity wave momentum flux (GWMF), potential energy density, and other quantitative wave properties (Ern et al., 2004; Fritts et al., 2014). The gravity wave retrieval involves several steps. The starting point is to infer spatial temperature variations, after calculation of a mean background temperature field. The three-dimensional temperature variations are then the basis for identifying horizontal and vertical wavelengths or wave numbers. Subsequent analysis builds on basic wave relationships as described, for example, by 
Fritts and Alexander (2003). Applying the dispersion relation, intrinsic frequency and group velocity can be inferred from wave numbers and background temperature. This is the basis for a subsequent retrieval of directional GWMF (Ern et al., 2004, 2011). This also needs (climatological) data on atmospheric density. Retrieval at multiple altitudes allows for an analysis of vertical GWMF gradients, and thus the momentum forcing (wave drag) of the background flow. An important goal is to obtain seasonal and latitudinal climatologies of gravity wave spectra, and to identify the contribution of different wavelengths to GWMF and wave drag. Such an analysis requires knowledge about a sensitivity function, i.e. the response of the MATS wave retrieval in terms of a wave's horizontal and vertical wavelength, and orientation, as well as observation conditions. Detailed descriptions of wave retrievals and sensitivities are beyond the scope of the current paper and will be provided in future publications about MATS data products.

In order to demonstrate MATS' ability to reconstruct gravity wave structures, the tomographic method has been tested on a set of coherent gravity waves observable in the atmospheric band emission. The emission field is generated using a simple airglow gravity wave model $(\mathrm{Li}, 2017)$. Using the same forward model as for the NLC simulations (Sect. 4.4), MATS limb instrument images are simulated, and the threedimensional emission fields are retrieved using the MAP method. A total of 200 images have been simulated, covering $6000 \mathrm{~km}$ along-track and $400 \mathrm{~km}$ across-track with a resolution of $5 \mathrm{~km} \times 5 \mathrm{~km} \times 0.25 \mathrm{~km}$.

This has been tested for wave structures aligned both along the movement of the satellite and perpendicular to it. As part of these tests, the horizontal and vertical wavelengths are varied. The amplitude of the retrieved wave is then compared to the amplitude of the true wave field. The ratio between these indicates the contrast in the retrieved data and is referred to as the gravity wave sensitivity for a certain wavelength (Preusse et al., 2002). Figure 11a shows the sensitivity for along-track waves, i.e. waves with fronts aligned perpendicular to the satellite track. Gravity waves with horizontal wavelengths down to $60 \mathrm{~km}$ and vertical wavelengths down to 3 to $5 \mathrm{~km}$ can be detected with a contrast better than 0.8. Panel (b) shows the sensitivity for across-track waves, i.e. waves with fronts parallel to the satellite track. For this wave geometry, vertical wavelengths can be inferred down to $3 \mathrm{~km}$ with a strong signal, and horizontal wavelengths can be retrieved down to $20 \mathrm{~km}$, only limited by the resolution of the limb image. For both along-track and across-track waves, wave structures with vertical wavelength down to $1 \mathrm{~km}$ can be detected, albeit with a reduction in amplitude by more than $50 \%$.

\section{Operational planning}

During routine operations, MATS will spend most of the time taking images using nominal science modes defined for the mission. Based on season and time of day, different atmospheric phenomena are to be observed and, hence, different imaging channels will operate. Beyond the nominal science modes, certain measurements must be performed in order to characterize the instrument in orbit. These calibration modes will be carried out with certain intervals and involve changes in control settings for both the payload and the platform. During normal operations a set of commands will be uploaded once per week. For commands that are required to be executed at a particular point in space, the timing of the commands will use predicted satellite orbits, based on orbit data ("two-line elements") gathered up to 2 weeks in advance.

\subsection{Science modes}

When defining operational measurement modes, an important constraint is the total data volume as defined by the satellite's downlink capacity. Hence, compromises must be made concerning image resolution, image compression, sampling interval, geographical coverage, and the number of channels in operation. "NLC modes" will be active during the NLC season, i.e. summer months in either hemisphere. During that period, the UV limb channels are given priority to operate at high resolution at summer latitudes poleward of $45^{\circ}$. The resolution of the IR limb channels is kept moderate in order to keep data volumes down. "IR modes" will be active outside the NLC season and involve no data collection in the UV channels, which allows the IR channels to operate at higher resolution. The IR nadir camera will always be operated during nighttime, producing a rather small data volume. Tables 5 and 6 summarize basic instrument settings in NLC and IR modes. Note that the exact values listed in the tables are preliminary. They are subject to change depending on the in-orbit performance, as will be established during the commissioning phase. The resulting measurements are the basis for the retrieval of the primary data product listed in Table 1.

In addition to the instrument settings in Tables 5 and 6 , the platform attitude can be adapted in accordance with specific measurement objectives. A standard viewing geometry is to take subsequent limb images centred around the satellite orbit plane. At the highest latitudes, this provides aligned images as input tomographic retrieval. However, at lower latitudes the Earth rotation leads to a continuous shifting of the atmospheric scene with respect to the orbit plane. MATS provides the option to compensate for this in terms of a continuous yaw movement of the satellite. This movement lets the limb field of view follow the Earth rotation, thus keeping a targeted section of the atmosphere aligned between subsequent limb images. 
Table 5. Preliminary scheme of the image readout in the six limb channels and the nadir channel during "NLC mode". Information about pixels refers to image pixels that are created from binning of the individual CCD pixels. The total image data amount to $8275 \mathrm{kB}$ per orbit.

\begin{tabular}{lrrrrrrl}
\hline NLC mode (1 May-10 September, 1 November-10 March) \\
\hline Channel & UV1 & UV2 & IR1 & IR2 & IR3 & IR4 & Nadir \\
Horizontal pixel size (km) & 5 & 5 & 10 & 10 & 50 & 50 & $10 \times 10$ \\
Vertical pixel size (km) & 0.2 & 0.2 & 0.4 & 0.4 & 0.8 & 0.8 & n/a \\
Number of across-track pixels & 50 & 50 & 25 & 25 & 5 & 5 & 18.5 \\
Number of vertical pixels & 200 & 200 & 138 & 138 & 69 & 69 & n/a \\
Readout interval (s) & 3 & 3 & 5 & 5 & 5 & 5 & $\sim 1.4$ \\
Integration time (s) & $<3$ & $<3$ & $<5$ & $<5$ & $<5$ & $<5$ & 1 \\
JPEG quality (\%) & 90 & 90 & 90 & 90 & 90 & 90 & n/a \\
Data per image (kB) & 4.31 & 4.31 & 1.49 & 1.49 & 0.15 & 0.15 & 0.08 \\
Active fraction of orbit (\%) & 30 & 30 & 100 & 100 & 100 & 100 & 30 \\
Images per orbit & 540 & 540 & 1080 & 1080 & 1080 & 1080 & 1157 \\
Data per orbit (kB) & 2325 & 2325 & 1604 & 1604 & 160 & 160 & 96 \\
\hline
\end{tabular}

n/a: not applicable.

Table 6. Preliminary scheme of the image readout in the six limb channels and the nadir channel during "IR mode". Information about pixels refers to image pixels that are created from binning of the individual CCD pixels. The total image data amount to $8373 \mathrm{kB}$ per orbit.

\begin{tabular}{lccrrrrl}
\hline IR Mode (11 March-30 April, 11 & September-31 & October) & & & \\
\hline Channel & UV1 & UV2 & IR1 & IR2 & IR3 & IR4 & Nadir \\
Horizontal pixel size (km) & - & - & 5 & 5 & 50 & 50 & $10 \times 10$ \\
Vertical pixel size (km) & - & - & 0.4 & 0.4 & 0.8 & 0.8 & n/a \\
Number of across-track pixels & - & - & 50 & 50 & 5 & 5 & 18.5 \\
Number of vertical pixels & - & - & 138 & 138 & 69 & 69 & n/a \\
Readout interval (s) & - & - & 5 & 5 & 5 & 5 & $\sim 1.4$ \\
Integration time (s) & - & - & $<5$ & $<5$ & $<5$ & $<5$ & 1 \\
JPEG quality (\%) & - & - & 94 & 94 & 94 & 94 & n/a \\
Data per image (kB) & - & - & 3.68 & 3.68 & 0.18 & 0.18 & 0.08 \\
Active fraction of orbit (\%) & 0 & 0 & 100 & 100 & 100 & 100 & 10 \\
Images per orbit & 0 & 0 & 1080 & 1080 & 1080 & 1080 & 386 \\
Data per orbit (kB) & 0 & 0 & 3972 & 3972 & 199 & 199 & 32 \\
\hline
\end{tabular}

n/a: not applicable.

\subsection{Calibration modes}

In addition to the above science modes, a number of measurements are to be performed to characterize the instrument in orbit. Calibration measurements will be carried out with certain intervals, and involve changes in control settings for both the payload and the platform. Moreover, special manoeuvres can be performed to verify the integrity of the instrument after launch or on other occasions.

The driver for these calibration and special modes is that instrument properties may change in time, and need to be monitored. Table 7 lists main properties in this regard, including satellite operations and timescales over which changes can occur. These properties may in turn be dependent on operational parameters like solar position, instrument temperature etc., and should be monitored together as a function of those, if applicable. For these characterization activities, dedicated attitude operations have been defined for the platform, e.g. providing the possibility to point towards the lower (Rayleigh scattering) atmosphere, dark space, the moon, or stars. During these measurements the CCDs may be operated with different integration times, with reduced pixel binning or full image readout.

\section{Outlook}

In the late 1950s, Georg Witt laid the foundation for mesospheric research in Sweden. Studying NLCs using groundbased photography, he applied stereoscopic analysis to infer three-dimensional structures of the clouds (Witt, 1962). Sixty years later, the MATS satellite is about to study threedimensional structures in the mesosphere by tomographic observations from space. Georg Witt passed away in 2014, but he was still with us when MATS was proposed and se- 
Table 7. Properties of the MATS limb instrument that need to be characterized during the mission.

\begin{tabular}{lll}
\hline Property & Satellite operation & Timescale \\
\hline Dark current & Pointing into darkness & Weeks \\
Readout bias & Pointing into darkness & Months \\
Bad pixels & Pointing into darkness & Weeks \\
Noise level & Pointing into darkness & Months \\
Polarization sensitivity & Role motion, pointing to various altitudes & Years \\
Stray light & Limb scanning from brighter lower altitudes to darkness & Years \\
Point spread function & Pointing at stars & Years \\
Relative spectral calibration & Pointing at moon, Pointing to lower altitudes. & Years \\
Absolute calibration & Pointing to lower atmosphere, Pointing at moon & Months \\
Instrument pointing & Pointing at stars & Months \\
\hline
\end{tabular}

lected earlier the same year. His scientific ideas will be with us when MATS flies.

At the time this paper was written, MATS was being prepared to be ready for a launch in 2020. Platform, instruments, and system have passed critical design reviews and are now going through assembly, integration, and testing. Pre-flight calibration procedures have been developed and are being applied to characterize instrument properties like imaging quality, sensitivity, spectral and polarization dependence, dark current, and other CCD characteristics. In parallel, procedures and software are being developed for data handling, tomographic and spectroscopic retrieval, and scientific analysis.

Basic measurement targets in the upper mesosphere and lower thermosphere are $\mathrm{O}_{2}$ atmospheric band airglow and NLCs. From these, the primary data products emission rate, temperature, atomic oxygen, and ozone as well as NLC brightness and particle size will be retrieved (Table 1). Based on these three-dimensional data products, an analysis in terms of gravity waves and other dynamical structures will be conducted. This needs essentially two steps: first, (wave) structures need to be identified, which involves appropriate filtering against noise and small-scale fluctuations; second, accessible wave parameters like horizontal and vertical wavelengths, wave orientation, and momentum flux will be addressed. The resulting wave climatology can be analysed, e.g. in terms of wave spectra, as a function of latitude and season, and in relationship to dynamic conditions and drivers in other parts of the atmosphere. Co-analysis with other missions and meteorological data will be central to these efforts. Modelling efforts will be decisive to combine different parts of these studies into the larger picture of atmospheric dynamics.

At all stages of the above analysis, collaboration with other research groups will be necessary and highly welcome. This concerns both the MATS dynamics objectives and mesospheric cloud objectives as defined in Sect. 1.1. The launch of the MATS satellite will be followed by an intense period of consolidating observational data and retrieval methods. Initial work on the scientific analysis will then be conducted by a core team of collaborating research groups. This will soon be followed by general releases of data products on the different levels.

As for NLC studies, there will be a natural connection to the Odin satellite mission, providing a comprehensive OSIRIS NLC climatology of 17 years so far (Gumbel and Karlsson, 2011). Beyond climatology, as the orbits of MATS and Odin will be in close proximity, there are also perspectives towards more direct co-analysis on an orbit-to-orbit basis. Based on overlapping orbits, true common-volume NLC studies are envisaged between MATS and AIM/CIPS. This follows the path already laid out by common volume studies between AIM and Odin (Benze et al., 2018; Broman et al., 2019). Joint studies by CIPS and MATS will make use of the complementary nature of the missions with the highly resolved horizontal data of CIPS and the three-dimensional tomographic data of MATS.

An example of a "whole atmosphere" perspective is a collaboration envisaged between MATS and several NASA missions, together providing the potential of gravity wave studies ranging from the troposphere to the thermosphere. Various methods for gravity wave analysis have been developed for AQUA/AIRS from the troposphere to mid-stratosphere (e.g. Hoffmann and Alexander, 2009; Gong et al., 2012), for AIM/CIPS in the stratopause region (Randall et al., 2017), and for the ionosphere-thermosphere missions Global-scale Observations of the Limb and Disk (GOLD) (Greer et al., 2018) and Ionospheric Connection Explorer (ICON) (Immel et al., 2018). As a complement to these missions, the MATS gravity wave analysis fills an important gap in upper mesosphere studies. As described in the introduction, these perspectives coincide with an era of increasing model abilities to explicitly simulate gravity waves from tropospheric sources to effects in the middle and upper atmosphere (H.L. Liu et al., 2014; Watanabe et al., 2015; Becker and Vadas, 2018). An important basis for linking MATS results to the dynamics of the troposphere and stratosphere will also be the co-analysis with meteorological datasets. In particular, highresolution data from the Integrated Forecasting System (IFS) of the European Centre for Medium-Range Weather Fore- 
casts (ECMWF) have been shown to well reproduce gravity wave activity throughout the stratosphere (Dörnbrack et al., 2017; Ehard et al., 2018).

On a local basis, the three-dimensional MATS data will provide new opportunities for joint studies with groundbased instrumentation. Ground-based networks with a focus on wave analysis like the ARISE project will be of particular interest (Blanc et al., 2018). In the field of NLCs and related mesospheric ice phenomena, local measurements include lidar and MST radar. In the field of airglow, local measurements include ground-based nightglow imaging and related spectroscopic temperature analysis. Wave studies in the MLT will also benefit from coincident MATS tomography and local time- and altitude-resolved measurements of wind (e.g. by meteor radar) or temperature (e.g. by resonance lidar). On an even more detailed level, co-analysis is possible between three-dimensional MATS data fields and coincident sounding rocket experiments. It is important to note that many of these local studies also provide valuable possibilities to validate MATS measurements and analysis methods. Extending local co-analysis into the thermosphere and ionosphere, the objectives of MATS are closely related to scientific goals of the EISCAT_3D incoherent scatter radar system (Aikio et al., 2014) and other radar networks. Three-dimensional data fields from both measurement systems can lead to intriguing new studies on dynamical structures and coupling processes across the MLT.

Data availability. Once the MATS satellite will be in orbit, data products on different levels will be made publically available.

Author contributions. JG, LM, OMC, DPM, JS, BK, and GW contributed to the conceptional development of the MATS science mission. LM and OMC were project leaders for the MATS instrument development; JG, NK, and DPM contributed to the overall coordination of the project. OMC, JD, GG, JG, AH, JH, NI, MK, AL, SM, LM, DPM, GO, JR, and JS worked with the development of instruments, retrieval, and scientific analysis. SC, SP, WP, and AH designed the limb telescope. JG, DPM, NI, and BK contributed to the acquisition of financial support for the mission. JG, OMC, LM, and NK prepared the paper with contributions from the co-authors.

Competing interests. The authors declare that they have no conflict of interest.

Special issue statement. This article is part of the special issue "Layered phenomena in the mesopause region (ACP/AMT interjournal SI)". It is a result of the LPMR workshop 2017 (LPMR2017), Kühlungsborn, Germany, 18-22 September 2017.
Acknowledgements. We thank the teams at Omnisys Instruments, OHB-Sweden, and ÅAC Mictrotec. Their dedicated engineering and management work has made the MATS payload and the InnoSat/MATS satellite platform possible. The scientific development of the mission has benefitted greatly from discussions with many scientists. We are particularly grateful to Gerd Baumgarten, Erich Becker, Adam Bourassa, Doug Degenstein, Patrick Eriksson, Manfred Ern, Patrick Espy, Craig Haley, Mark Hervig, Martin Kaufmann, Yvan Orsolini, Kristell Pérot, Dave Rusch, Kaoru Sato, Mike Stevens, Mike Taylor, Christian von Savigny, Sharon Vadas, and Kaley Walker. We thank Andreas Fjeldstad, Björn Linder, Markus Janghede, Franz Kanngieser, Tobias Kuremyr, Daniel Pettersson, Simon Pfreundschuh, Tejaswi Seth, and Sarah Zayouna for their contributions to instrument development, instrument characterization, and retrieval development. We thank Susanne Benze, Lina Broman, Koen Hendrickx, Maartje Kuilman, and Marin Stanev for their engagement in the MATS science questions. The MATS project is funded by the Swedish National Space Agency (SNSA), and we especially acknowledge the commitment of their representative Ronnie Lindberg.

Financial support. This research has been supported by the Swedish National Space Agency (grant nos. 21/15, 297/17). Additional financial support has been provided by the Erna and Victor Hasselblad Foundation (grant no. EVH2017-10). The development of the off-axis telescope was supported by the National Research Foundation of Korea (grant no. NRF-2014M1A3A3A02034810, BK21 plus programme).

The article processing charges for this open-access publication were covered by Stockholm University.

Review statement. This paper was edited by William Ward and reviewed by three anonymous referees.

\section{References}

Aikio, A., McCrea, I., and the EISCAT_3D Science Working Groups: EISCAT 3D Science Case, Report for the EISCAT 3D Preparatory Phase Project WP3, EISCAT Scientifc Association, Kiruna, Sweden, 2014.

Akmaev, R. A.: Whole atmosphere modeling: Connecting terrestrial and space weather, Rev. Geophys., 49, RG4004, https://doi.org/10.1029/2011RG000364, 2011.

Alexander, M. J.: Global and seasonal variations in threedimensional gravity wave momentum flux from satellite limbsounding temperatures, Geophys. Res. Lett., 42, 6860-6867, https://doi.org/10.1002/2015GL065234, 2015.

Alexander, M. J., Geller, M., McLandress, C., Polavarapu, S., Preusse, P., Sassi, F., Sato, K., Eckermann, S., Ern, M., Hertzog, A., Kawatani, Y., Pulido, M., Shaw, T. A., Sigmond, M., Vincent, R., and Watanabe, S.: Recent developments in gravity-wave effects in climate models and the global distribution of gravitywave momentum flux from observations and models, Q. J. Roy. Meteorol. Soc., 136, 1103-1124, https://doi.org/10.1002/qj.637, 2010 . 
Anderson, D. N.: Modeling the ambient, low latitude F-region ionosphere - a review, J. Atmos. Terr. Phys., 43, 753-762, 1981.

Azeem, I., Yue, J., Hoffmann, L., Miller, S. D., Straka III, W. C., and Crowley, G.: Multisensor pro?ling of a concentric gravity wave event propagating from the troposphere to the ionosphere, Geophys. Res. Lett., 42, 7874-7880, https://doi.org/10.1002/2015GL065903, 2015.

Babcock, H. D. and Herzberg, L.: Fine structure of the red system of atmospheric oxygen bands, Astrophys. J., 108, 167-190, https://doi.org/10.1086/145062, 1948.

Becker, E.: Dynamical Control of the Middle Atmosphere, Space Sci. Rev., 168, 283-314, https://doi.org/10.1007/s11214-0119841-5, 2012.

Becker, E. and Vadas, S. L.: Secondary gravity waves in the winter mesosphere: Results from a high-resolution global circulation model, J. Geophys. Res., 123, 2605-2627, 2018.

Becker E., Müllemann, A., Lübken, F.-J., Körnich, H., Hoffmann, P., and Rapp, M.: High Rossby-wave activity in austral winter 2002: Modulation of the general circulation of the MLT during the MaCWAVE/MIDAS northern summer program, Geophys. Res. Lett., 31, L24S03, https://doi.org/10.1029/2004GL019615, 2004

Benze, S., Gumbel, J., Randall, C. E., Karlsson, K., Hultgren, K., Lumpe, J. D., and Baumgarten, G.: Making limb and nadir measurements comparable: A common volume study of PMC brightness observed by Odin OSIRIS and AIM CIPS, J. Atmos. Sol.-Terr. Phy., 167, 66-73, https://doi.org/10.1016/j.jastp.2017.11.007, 2018.

Blanc, E., Ceranna, L., Hauchecorne, A., Charlton-Perez, A., Marchetti, E., Evers, L. G., Kvaerna, T., Lastovicka, J., Eliasson, L., Crosby, N. B., Blanc-Benon, P., Le Pichon, A., Brachet, N., Pilger, C., Keckhut, P., Assink, J. D., Smets, P. S. M., Lee, C. F., Kero, J., Sindelarova, T., Kämpfer, N., Rüfenacht, R., Farges, T., Millet, C., Näsholm, S. P., Gibbons, S. J., Espy, P. J., Hibbins, R. E., Heinrich, P., Ripepe, M., Khaykin, S., Mze, N., and Chum, J.: Toward an improved representation of middle atmospheric dynamics thanks to the ARISE project, Surv. Geophys., 39, 171-225, https://doi.org/10.1007/s10712-017-9444-0, 2018.

Bourassa, A., Degenstein, D., and Llewellyn, E. J.: SASKTRAN: A spherical geometry radiative transfer code for efficient estimation of limb scattered sunlight, J. Quant. Spectrosc. Ra., 107, 52-73, 2008.

Broman, L., Benze, S., Gumbel, J., Christensen, O.-M., and Randall, C. E.: Common volume satellite studies of polar mesospheric clouds with Odin/OSIRIS tomography and AIM/CIPS nadir imaging, Atmos. Chem. Phys. Discuss., https://doi.org/10.5194/acp-2018-1035, in review, 2019.

Carbary, J. F., Morrison, D., and Romick, G. J.: Transpolar structure of polar mesospheric clouds, J. Geophys. Res., 105, 2476324769, 2000.

Carlotti, M., Dinelli, B. M., Raspollini, P., and Ridolfi, M.: Geo-fit approach to the analysis of limb-scanning satellite measurements, Appl. Optics, 40, 1872-1885, https://doi.org/10.1364/ORS.2001.OWC5, 2001.

Chandran, A., Rusch, D., Palo, S. E., Thomas, G. E., and Taylor, M.: Gravity wave observatiosn from the Cloud Imaging and Particle Size (CIPS) experiment on the AIM Spacecraft, J. Atmos. Sol.-Terr. Phy., 71, 392-400, https://doi.org/10.1016/j.jastp.2008.09.041, 2009.
Chang, S.: Linear astigmatism of confocal off-axis reflective imaging systems with $\mathrm{N}$-conic mirrors and its elimination, J. Opt. Soc. Am. A, 32, 852-859, https://doi.org/10.1364/JOSAA.32.000852, 2015.

Chau, J. L., Goncharenko, L. P., Fejer, B. G., and Liu, H.-L.: Equatorial and low latitude ionospheric effects during sudden stratospheric warming events, Space Sci. Rev., 168, 385-417, https://doi.org/10.1007/s11214-011-9797-5, 2011.

Chen, P.-R.: Two-day oscillation of the Equatorial Ionization Anomaly, J. Geophys. Res., 97, 6343-6357, 1992.

Christensen, O. M., Eriksson, P., Urban, J., Murtagh, D., Hultgren, K., and Gumbel, J.: Tomographic retrieval of water vapour and temperature around polar mesospheric clouds using Odin-SMR, Atmos. Meas. Tech., 8, 1981-1999, https://doi.org/10.5194/amt8-1981-2015, 2015

Christensen, O. M., Benze, S., Eriksson, P., Gumbel, J., Megner, L., and Murtagh, D. P.: The relationship between polar mesospheric clouds and their background atmosphere as observed by OdinSMR and Odin-OSIRIS, Atmos. Chem. Phys., 16, 12587-12600, https://doi.org/10.5194/acp-16-12587-2016, 2016.

Degenstein, D. A., Llewellyn, E. J., and Lloyd, N. D.: Volume emission rate tomography from a satellite platform, Appl. Optics, 42, 1441-1450, 2003.

Degenstein, D. A., Llewellyn, E. J., and Lloyd, N. D.: Tomographic retrieval of the oxygen infrared atmospheric band with the OSIRIS infrared imager, Can. J. Phys., 82, 501-515, 2004.

de Wit, R. J., Hibbins, R. E., Espy, P. J., Orsolini, Y. J., Limpasuvan, V., and Kinnison, D. E.: Observations of gravity wave forcing of the mesopause region during the January 2013 major Sudden Stratospheric Warming, Geophys. Res. Lett., 41, 4745-4752, https://doi.org/10.1002/2014GL060501, 2014.

Dörnbrack, A., Gisinger, S., Pitts, M. C., Poole, L. R., and Maturilli, M.: Multilevel cloud structure over Svalbard, Mon. Weather Rev., 145, 1149-1159, https://doi.org/10.1175/MWRD-16-0214.1, 2017.

Ehard, B., Malardel, S., Dörnbrack, A., Kaifler, B., Kaifler, N., and Wedi, N.: Comparing ECMWF high resolution analyses to 20 lidar temperature measurements in the middle atmosphere, Q. J. Roy. Meteorol. Soc., 144, 633-640, https://doi.org/10.1002/qj.3206, 2018.

Ern, M., Preusse, P., Alexander, M. J., and Warner, C. D.: Absolute values of gravity wave momentum flux derived from satellite data, J. Geophys. Res., 109, D20103, https://doi.org/10.1029/2004JD004752, 2004.

Ern, M., Preusse, P., Gille, J. C., Hepplewhite, C. L., Mlynczak, M. G., Russell III, J. M., and Riese, M.: Implications for atmospheric dynamics derived from global observations of gravity wave momentum flux in stratosphere and mesosphere, J. Geophys. Res., 116, D19107, https://doi.org/10.1029/2011JD015821, 2011.

Ern, M., Preusse, P., Kalisch, S., Kaufmann, M., and Riese, M.: Role of gravity waves in the forcing of quasi two-day waves in the mesosphere: An observational study, J. Geophys. Res., 118, 3467-3485, https://doi.org/10.1029/2012JD018208, 2013.

Ern, M., Trinh, Q. T., Kaufmann, M., Krisch, I., Preusse, P., Ungermann, J., Zhu, Y., Gille, J. C., Mlynczak, M. G., Russell III, J. M., Schwartz, M. J., and Riese, M.: Satellite observations of middle atmosphere gravity wave absolute momentum flux and of its vertical gradient during recent stratospheric warmings, At- 
mos. Chem. Phys., 16, 9983-10019, https://doi.org/10.5194/acp16-9983-2016, 2016.

Ern, M., Hoffmann, L., and Preusse, P.: Directional gravity wave momentum fluxes in the stratosphere derived from highresolution AIRS temperature data, Geophys. Res. Lett., 44, 475485, https://doi.org/10.1002/2016GL072007, 2017.

Espy, P. J., Jones, G. O. L., Swenson, G. R., Tang, J., and Taylor, M. J.: Seasonal variations of the gravity wave momentum flux in the Antarctic mesosphere and lower thermosphere, J. Geophys. Res., 109, D23109, https://doi.org/10.1029/2003JD004446, 2004.

Evans, W., McDade, I., Yuen, J., and Llewellyn, E.: A rocket measurement of the $\mathrm{O}_{2}$ infrared atmospheric (0-0) band emission in the dayglow and a determination of the mesospheric ozone and atomic oxygen densities, Can. J. Phys., 66, 941-946, 1988.

Forbes, J. M. and Leveroni, S.: Quasi 16-day oscillation in the ionosphere, Geophys. Res. Lett., 19, 981-984, 1992.

Forbes, J. M., Zhang, X., Palo, S. E., Russell III, J. M., Mertens, C. J., and Mlynczak, M. G.: Kelvin waves in stratosphere, mesosphere and lower thermosphere temperatures as observed by TIMED/SABER during 2002-2006, Earth Planets Space, 61, 447-453, 2009.

Forbes, J. M., Bruinsma, S. L., Doornbos, E., and Zhang, X.: Gravity wave-induced variability of the middle thermosphere, J. Geophys. Res.-Space, 121, 6914-6923, https://doi.org/10.1002/2016JA022923, 2016.

Fritts, D. C. and Alexander, M. J.: Gravity wave dynamics and effects in the middle atmosphere, Rev. Geophys., 41, 1003, https://doi.org/10.1029/2001RG000106, 2003.

Fritts, D. C., Vadas, S. L., Wan, K., and Werne, J. A.: Mean and variable forcing of the middle atmosphere by gravity waves, J. Atmos Sol.-Terr. Phys., 68, 247-265, https://doi.org/10.1016/j.jastp.2005.04.010, 2006.

Fritts, D. C., Pautet, P.-D., Bossert, K., Taylor, M. J., Williams, B. P., Iimura, H., Yuan, T., Mitchell, N. J., and Stober, G.: Quantifying gravity wave momentum fluxes with Mesosphere Temperature Mappers and correlative instrumentation, J. Geophys. Res.-Atmos., 119, 13583-13603, https://doi.org/10.1002/2014JD022150, 2014.

Funke, B., López-Puertas, M., Bermejo-Pantaleón, D., GarcíaComas, M., Stiller, G. P., von Clarmann, T., Kiefer, M., and Linden, A.: Evidence for dynamical coupling from the lower atmosphere to the thermosphere during a major stratospheric warming, Geophys. Res. Lett., 37, L13803, https://doi.org/10.1029/2010GL043619, 2010.

Gao, H., Li, L., Bu, L., Zhang, Q., Tang, Y., and Wang, Z.: Effect of Small-Scale Gravity Waves on Polar Mesospheric Clouds Observed From CIPS/AIM, J. Gophys. Res., 123, 4026-4045, https://doi.org/10.1029/2017JA024855, 2018.

Geller, M. A., Alexander, M. J., Love, P. T., Bacmeister, J., Ern, M., Hertzog, A., Manzini, E., Preusse, P., Sato, K., Scaife, A. A., and Zhou, T.: A comparison between gravity wave momentum fluxes in observations and climate models, J. Climate, 26, 6383-6405, 2013.

Giono, G., Olentšenko, G., Ivchenko, N., Christensen, O. M., Gumbel, J., Frisk, U., Hammar, A., Davies, I., Megner, L., and the MATS team: Characterisation of the analogue read-out chain for the CCDs onboard the Mesospheric Airglow/Aerosol Tomography and Spectroscopy (MATS), Proc. SPIE, 10698, 1-8, https://doi.org/10.1117/12.2313732, 2018.
Gong, J., Wu, D. L., and Eckermann, S. D.: Gravity wave variances and propagation derived from AIRS radiances, Atmos. Chem. Phys., 12, 1701-1720, https://doi.org/10.5194/acp-121701-2012, 2012.

Greer, K. R., England, S. L., Becker, E., Rusch, D., and Eastes, R.: Modeled gravity wave-like perturbations in the brightness of far ultraviolet emissions for the GOLD mission, J. Geophys. Res., 123, 5821-5830, https://doi.org/10.1029/2018JA025501, 2018.

Gumbel, J. and Karlsson, B.: Intra- and inter-hemispheric coupling effects on the polar summer mesosphere, Geophys. Res. Lett., 38, L14804, https://doi.org/10.1029/2011GL047968, 2011.

Hammar, A., Christensen, O. M., Park, W., Pak, S., Emrich, A., and Stake, J.: Stray light suppression of a compact off-axis telescope for a satellite-borne instrument for atmospheric research, Proc. SPIE 10815, Optical Design and Testing VIII, 108150F, https://doi.org/10.1117/12.2500555, 2018.

Hammar, A., Park, W., Chang, S., Pak, S., Emrich, A., and Stake, J.: Wide-field off-axis telescope for the Mesospheric Airglow/Aerosol Tomography Spectroscopy satellite, Appl. Optics, 58, 1393-1399, https://doi.org/10.1364/AO.58.001393, 2019.

Hart, V. P., Taylor, M. J., Doyle, T. E., Zhao, Y., Pautet, P.-D., Carruth, B. L., Rusch, D. W., and Russell, J. M.: Investigating gravity waves in polar mesospheric clouds using tomographic reconstructions of AIM satellite imagery, J. Geophys. Res., 123, 955973, https://doi.org/10.1002/2017JA024481, 2018.

Hoffmann, L. and Alexander, M. J.: Retrieval of stratospheric temperatures from Atmospheric Infrared Sounder radiance measurements for gravity wave studies, J. Geophys. Res., 114, D07105, https://doi.org/10.1029/2008JD011241, 2009.

Holton, J. R.: The role of gravity wave induced drag and diffusion in the momentum budget of the mesosphere, J. Atmos. Sci., 39, 791-799, https://doi.org/10.1175/15200469(1982)039<0791:TROGWI>2.0.CO;2, 1982.

Holton, J. R.: The generation of mesospheric planetary waves by zonally asymmetric gravity wave breaking, J. Atmos. Sci., 41, 3427-3430, https://doi.org/10.1175/15200469(1984)041<3427:TGOMPW>2.0.CO;2, 1984.

Hultgren, K. and Gumbel, J.: Tomographic and spectral views on the lifecycle of polar mesospheric clouds from Odin/OSIRIS, J. Geophys. Res., 119, 14129-14143, https://doi.org/10.1002/2014JD022435, 2014.

Hultgren, K., Gumbel, J., Degenstein, D., Bourassa, A., Lloyd, N. D., and Stegman, J.: First simultaneous retrievals of horizontal and vertical structures of Polar Mesospheric Clouds from Odin/OSIRIS tomography, J. Atmos. Sol.-Terr. Phy., 104, $213-$ 223, 2013.

Immel, T. J., England, S. L., Mende, S. B., Heelis, R. A., Englert, C. R., Edelstein, J. , Frey, H. U., Korpela, E. J., Taylor, E.R., Craig, W. W., Harris, S. E., Bester, M., Bust, G. S., Crowley, G., Forbes, J. M., Gérard, J.-C., Harlander, J. M., Huba, J. D., Hubert, B. , Kamalabadi, F., Makela, J. J., Maute, A. I., Meier, R. R., Raftery, C., Rochus, P., Siegmund, O. H. W., Stephan, A. W., Swenson, G. R., Frey, S., Hysell, D. L., Saito, A., Rider, K. A., and Sirk, M. M.: The Ionospheric Connection Explorer Mission: mission goals and design, Space Sci. Rev., 214, 13, https://doi.org/10.1007/s11214-017-0449-2, 2018.

Kaifler, N., Kaifler, B., Wilms, H., Rapp, M., Stober, G., and Jacobi, C.: Mesospheric temperature during the extreme midlatitude noctilucent cloud event on 18/19 July 2016, J. Geophys. Res., 
123, 13775-13789, https://doi.org/10.1029/2018JD029717, 2018.

Kalisch, S., Preusse, P., Ern, M., Eckermann, S. D., and Riese, M.: Differences in gravity wave drag between realistic oblique and assumed vertical propagation, J. Geophys. Res.-Atmos., 119, 10081-10099, https://doi.org/10.1002/2014JD021779, 2014.

Karlsson, B. and Becker, E.: How does interhemispheric coupling contribute to cool down the summer polar mesosphere?, J. Climate, 29, 8807-8821, https://doi.org/10.1175/JCLI-D-160231.1, 2016

Karlsson, B. and Gumbel, J.: Challenges in the limb retrieval of noctilucent cloud properties from Odin/OSIRIS, Adv. Space Res., 36, 935-942, 2005.

Karlsson, B. and Shepherd, T. G.: The improbable clouds at the edge of the atmosphere, Phys. Today, 71, 30-36, https://doi.org/10.1063/PT.3.3946, 2018.

Karlsson, B., Körnich, H., and Gumbel, J.: Evidence for interhemispheric stratosphere-mesosphere coupling derived from noctilucent cloud properties, Geophys. Res. Lett., 34, L16806, https://doi.org/10.1029/2007GL030282, 2007.

Karlsson, B., Randall, C. E., Shepherd, T. G., Harvey, V. L., Lumpe, J., Nielsen, K., Bailey, S. M., Hervig, M., and Russell III, J. M.: On the onset of polar mesospheric clouds and the breakdown of the stratospheric polar vortex in the southern hemisphere, J. Geophys. Res., 116, D18107, https://doi.org/10.1029/2011JD015989, 2011.

Kaufmann, M., Blank, J., Guggenmoser, T., Ungermann, J., Engel, A., Ern, M., Friedl-Vallon, F., Gerber, D., Grooß, J. U., Guenther, G., Hö pfner, M., Kleinert, A., Kretschmer, E., Latzko, Th., Maucher, G., Neubert, T., Nordmeyer, H., Oelhaf, H., Olschewski, F., Orphal, J., Preusse, P., Schlager, H., Schneider, H., Schuettemeyer, D., Stroh, F., Suminska-Ebersoldt, O., Vogel, B., M. Volk, C., Woiwode, W., and Riese, M.: Retrieval of threedimensional small-scale structures in upper-tropospheric/lowerstratospheric composition as measured by GLORIA, Atmos. Meas. Tech., 8, 81-95, https://doi.org/10.5194/amt-8-81-2015, 2015.

Körnich, H. and Becker, E.: A simple model for the interhemispheric coupling of the middle atmosphere circulation, Adv. Space Res., 45, 661-668, https://doi.org/10.1016/j.asr.2009.11.001, 2010.

Krebsbach, M. and Preusse, P.: Spectral analysis of gravity wave activity in SABER temperature data, Geophys. Res. Lett., 34, L03814, https://doi.org/10.1029/2006GL028040, 2007.

Krisch, I., Ungermann, J., Preusse, P., Kretschmer, E., and Riese, M.: Limited angle tomography of mesoscale gravity waves by the infrared limb-sounder GLORIA, Atmos. Meas. Tech., 11, 43274344, https://doi.org/10.5194/amt-11-4327-2018, 2018.

Larsson, N., Lilja, R., Gumbel, J., Christensen, O. M., and Örth, M.: The MATS micro satellite mission - tomographic perspective on the mesosphere, ESA Proceedings of the 4s Symposium, Valletta, Malta, May 2016, 11070-11078, 2016.

$\mathrm{Li}, \mathrm{A}$.: A 3D-model for $\mathrm{O}_{2}$ airglow perturbations induced by gravity waves in the upper mesosphere, MSc thesis, Chalmers University of Technology, Göteborg, Sweden, 2017.

Limpasuvan, V., Wu, D. L., Schwartz, M. J., Waters, J. W., Wu, Q., and Killeen, T. L.: The two-day wave in EOS MLS temperature and wind measurements during 2004-2005 winter, Geophys.
Res. Lett., 32, L17809, https://doi.org/10.1029/2005GL023396, 2005.

Lindzen, R. S.: Turbulence and stress owing to gravity wave and tidal breakdown, J. Geophys. Res., 86, 9707-9714, https://doi.org/10.1029/JC086iC10p09707, 1981.

Liu, H.-L., Marsh, D. R., She, C.-Y., Wu, Q., and Xu, J.: Momentum balance and gravity wave forcing in the mesosphere and lower thermosphere, Geophys. Res. Lett., 36, L07805, https://doi.org/10.1029/2009GL037252, 2009.

Liu, H.-L., McInerney, J., Santos, S., Lauritzen, P. H., Taylor, M. A., and Pedatella, N. M.: Gravity waves simulated by high-resolution Whole Atmosphere Community Climate Model, Geophys. Res. Lett., 41, 9106-9112, https://doi.org/10.1002/2014GL062468, 2014.

Liu, X., Yue, J., Xu, J., Wang, L., Yuan, W., Russell III, J. M., and Hervig, M. E.: Gravity wave variations in the polar stratosphere and mesosphere from SOFIE/AIM temperature observations, J. Geophys. Res., 119, 7368-7381, https://doi.org/10.1002/2013JD021439, 2014.

Livesey, N. J., Van Snyder, W., Read, W. G., and Wagner, P. A.: Retrieval algorithms for the EOS microwave limb sounder (MLS), IEEE T. Geosci. Remote, 44, 1144-1155, 2006.

Llewellyn, E. J., Lloyd, N. D., Degenstein, D. A., Gattinger, R. L., Petelina, S. V., Bourassa, A. E., Wiensz, J. T., Ivanov, E. V., McDade, I. C., Solheim, B. H., McConnell, J. C., Haley, C. S., von Savigny, C., Sioris, C. E., McLinden, C. A., Griffioen, E., Kaminski, J., Evans, W. F. J., Puckrin, E., Strong, K., Wehrle, V., Hum, R. H., Kendall, D. J. W., Matsushita, J., Murtagh, D. P., Brohede, S., Stegman, J., Witt, G., Barnes, G., Payne, W. F., Piché, L., Smith, K., Warshaw. G., Deslauniers, D.-L., Marchand, P., Richardson, E. H., King, R. A., Wevers, I., McCreath, W., Kyrölä, E., Oikarinen, L., Leppelmeier, G. W., Auvinen, H., Mégie, G., Hauchecorne, A., Lefèvre, F., de La Nöe, J., Ricaud, P., Frisk, U., Sjöberg, F., von Schéele, F., and Nordh, L.: The OSIRIS instrument on the Odin spacecraft, Can. J. Phys., 82, 411-422, https://doi.org/10.1139/p04-005, 2004.

Lumpe, J. D., Bailey, S. M., Carstens, J. N., Randall, C. E., Rusch, D., Thomas, G. E., Nielsen, K., Jeppesen, C., McClintock, W. E., Merkel, A. W., Riesberg, L., Templeman, B., Baumgarten, G., and Russell III, J. M.: Retrieval of polar mesospheric cloud properties from CIPS: algorithm description, error analysis and cloud detection sensitivity, J. Atmos. Sol.-Terr. Phy., 104, 167196, https://doi.org/10.1016/j.jastp.2013.06.007, 2013.

Marks, C. J. and Eckermann, S. D.: A three-dimensional nonhydrostatic ray-tracing model for gravity waves: Formulation and preliminary results for the middle atmosphere, J. Atmos. Sci., 52, 1959-1984, 1995.

Marsh, D. R., Garcia, R. R., Kinnison, D. E., Boville, B. A., Sassi, F., Solomon, S. C., and Mathes, K.: Modeling the whole atmosphere response to solar cycle changes in radiative and geomagnetic forcing, J. Geophys. Res., 112, D23306, https://doi.org/10.1029/2006JD008306, 2007.

McDade, I., Murtagh, D., Greer, R., Dickinson, P., Witt, G., Stegman, J., Llewellyn, E., Thomas, L., and Jenkins, D.: ETON 2: Quenching parameters for the proposed precursors of $\mathrm{O}_{2}\left(b^{1} \Sigma_{g}^{+}\right)$and $\mathrm{O}\left({ }^{1} \mathrm{~S}\right)$ in the terrestrial nightglow, Planet. Space Sci., 34, 789-800, https://doi.org/10.1016/0032-0633(86)900759, 1986 
McLandress, C., Shepherd, T. G., Polavarapu, S., and Beagley, S. R.: Is missing orographic gravity wave drag near $60^{\circ} \mathrm{S}$ the cause of the stratospheric zonal wind biases in chemistry-climate models?, J. Atmos. Sci., 69, 802-818, https://doi.org/10.1175/JAS-D11-0159.1, 2012.

Megner, L., Christensen, O. M., Karlsson, B., Benze, S., and Fomichev, V. I.: Comparison of retrieved noctilucent cloud particle properties from Odin tomography scans and model simulations, Atmos. Chem. Phys., 16, 15135-15146, https://doi.org/10.5194/acp-16-15135-2016, 2016.

Megner, L., Stegman, J., Pautet, P.-D., and Taylor, M. J.: First observed temporal development of a noctilucent cloud ice void, Geophys. Res. Lett., 45, 10003-10010, https://doi.org/10.1029/2018GL078501, 2018.

Miller, S. D., Straka III, W. C., Yue, J., Smith, S. M., Alexander, M. J., Hoffmann, L., Setvák, M., and Partain, P. T.: Upper atmospheric gravity wave details revealed in nightglow satellite imagery, P. Natl. Acad. Sci. USA, 112, E6728-E6735, https://doi.org/10.1073/pnas.1508084112, 2015.

Mishchenko, M. I. and Travis, L. D.: Capabilities and limitations of a current FORTRAN implementation of the T-matrix method for randomly oriented, rotationally symmetric scatterers, J. Quant. Spectrosc. Radiat. Transfer, 60, 309-324, https://doi.org/10.1016/S0022-4073(98)00008-9, 1998.

Mlynczak, M. G., Morgan, F., Yee, J.-H., Espy, P., Murtagh, D., Marshall, B., and Schmidlin, F.: Simultaneous Measurements of the $\mathrm{O}_{2}\left({ }^{1} \Delta\right)$ and $\mathrm{O}_{2}\left({ }^{1} \Sigma\right)$ airglows and ozone in the daytime mesosphere, Geophys. Res. Lett., 28, 999-1002, 2001.

Murtagh, D. P., Witt, G., Stegman, J., McDade, I. C., Llewellyn, E. J., Harris, F., and Greer, R. G. H.: An assessment of proposed $\mathrm{O}\left({ }^{1} \mathrm{~S}\right)$ and $\mathrm{O}_{2}\left(b^{1} \Sigma_{g}^{+}\right)$nightglow excitation parameters, Planet. Space Sci., 38, 45-53, 1990.

Murtagh, D., Frisk, U., Merino, F., Ridal, M., Jonsson, A., Stegman, J., Witt, G., Eriksson, P., Jiménez, C., Megie, G., de la Noë, J., Ricaud, P., Baron, P., Pardo, J. R., Hauchcorne, A., Llewellyn, E. J., Degenstein, D. A., Gattinger, R. L., Lloyd, N. D., Evans, W. F. J., McDade, I. C., Haley, C. S., Sioris, C., von Savigny, C., Solheim, B.H., McConnell, J. C., Strong, K., Richardson, E. H., Leppelmeier, G. W., Kyrölä, E., Auvinen, H., and Oikarinen, L.: An overview of the Odin atmospheric mission, Can. J. Phys., 80, 309-319, 2002.

Oberheide, J., Forbes, J. M., Häusler, K., Wu, Q., and Bruinsma, S. L.: Tropospheric tides from 80 to $400 \mathrm{~km}$ : Propagation, interannual variability, and solar cycle effects, J. Geophys. Res., 114, D00I05, https://doi.org/10.1029/2009JD012388, 2009.

Park, J., Lühr, H., Lee, C., Kim, Y. H., Jee, G., and Kim, J.H.: A climatology of medium-scale gravity wave activity in the midlatitude/low-latitude daytime upper thermosphere as observed by CHAMP, J. Geophys. Res.-Space, 119, 2187-2196, https://doi.org/10.1002/2013JA019705, 2014.

Perwitasari, S., Sakanoi, T., Nakamura, T., Ejiri, M. K., Tsutsumi, M., Tomikawa, Y., Otsuka, Y., Yamazaki, A., and Saito, A.: Three years of concentric gravity wave variability in the mesopause as observed by IMAP/VISI, Geophys. Res. Lett., 43, 11528-11535, https://doi.org/10.1002/2016GL071511, 2016.

Plumb, R. A.: Baroclinic instability of the summer mesosphere: a mechanism for the quasi-two-day wave?, J. Atmos. Sci., 40, 262$270,1983$.
Preusse, P., Dörnbrack, A., Eckermann, S. D., Riese, M., Schaeler, B., Bacmeister, J. T., Broutman, D., and Grossmann, K. U.: Space-based measurements of stratospheric mountain waves by CRISTA, 1. Sensitivity, analysis method, and a case study, J. Geophys. Res., 107, 8178, https://doi.org/10.1029/2001JD000699, 2002.

Preusse, P., Ern, M., Eckermann, S. D., Warner, C. D., Picard, R. H., Knieling, P., Krebsbach, M., Russel III, J. M., Mlynczak, M. G., Mertens, C. J., and Riese, M.: Tropopause to mesopause gravity waves in August: measurement and modeling, J. Atmos. Sol.Terr. Phy., 68, 1730-1751, 2006.

Preusse, P., Eckermann, S. D., and Ern, M.: Transparency of the atmosphere to short horizontal wavelength gravity waves, J. Geophys. Res., 113, D24104, https://doi.org/10.1029/2007JD009682, 2008.

Preusse, P., Eckermann, S. D., Ern, M., Oberheide, J., Picard, R. H., Roble, R. G., Riese, M., Russell III, J. M., and Mlynczak, M. G.: Global ray tracing simulations of the SABER gravity wave climatology, J. Geophys. Res., 114, D08126, https://doi.org/10.1029/2008JD011214, 2009.

Randall, C. E., Carstens, J., France, J. A., Harvey, V. L., Hoffmann, L., Bailey, S. M., Alexander, M. J., Lumpe, J. D., Yue, J., Thurairajah, B., Siskind, D. E., Zhao, Y., Taylor, M. J., and Russell III, J. M.: New AIM/CIPS global observations of gravity waves near 50-55 km, Geophys. Res. Lett., 44, 7044-7052, https://doi.org/10.1002/2017GL073943, 2017.

Rapp, M. and Thomas, G. E.: Modeling the microphysics of mesospheric ice particles: Assessment of current capabilities and basic sensitivities, J. Atmos. Sol.-Terr. Phy., 68, 715-744, 2006.

Rapp, M., Lübken, F.-J., Müllemann, A., Thomas, G. E., and Jensen, E. J.: Small-scale temperature variations in the vicinity of NLC: Experimental and model results, J. Geophys. Res., 107, 4392, https://doi.org/10.1029/2001JD001241, 2002.

Roble, R. G.: On the feasibility of developing a global atmospheric model extending from the ground to the exosphere, in: Atmospheric Science Across the Stratopause, Geophys. Monogr. Ser., vol. 123, edited by: Siskind, D. E., Eckermann, S. D., and Summers, M. E., AGU, Washington, D.C., 53-67, 2000.

Rodgers, C. D.: Inverse methods for atmospheric sounding: theory and practice, World Scientific, River Edge, N.J., 2000.

Rong, P., Yue, J., Russell III, J. M., Siskind, D. E., and Randall, C. E.: Universal power law of the gravity wave manifestation in the AIM CIPS polar mesospheric cloud images, Atmos. Chem. Phys., 18, 883-899, https://doi.org/10.5194/acp-18-8832018, 2018.

Röttger, J.: Travelling disturbances in the equatorial ionosphere and their association with penetrative cumulus convection, J. Atmos. Terr. Phys., 39, 987-998, 1977.

Rusch, D. W., Thomas, G. E., McClintock, W., Merkel, A. W., Bailey, S. M., Russell III J. M., Randall, C. E., Jeppesen, C., and Callan, M.: The Cloud Imaging and Particle Size Experiment on the Aeronomy of Ice in the Mesosphere mission: Cloud morphology for the northern 2007 season, J. Atmos. Sol.-Terr. Phy., 71, 356-364, 2008.

Sato, K. and Nomoto, M.: Gravity-wave induced anomalous potential vorticity gradient generating planetary waves in the winter mesosphere, J. Atmos. Sci., 72, 3609-3624, https://doi.org/10.1175/JAS-D-15-0046.1, 2015. 
Sato, K., Watanabe, S., Kawatani, Y., Tomikawa, Y., Miyazaki, K., and Takahashi, M.: On the origins of mesospheric gravity waves, Geophys. Res. Lett., 36, L19801, https://doi.org/10.1029/2009GL039908, 2009.

Schmidt, T., Alexander, P., and de la Torre, A.: Stratospheric gravity wave momentum flux from radio occultations, J. Geophys. Res.-Atmos., 121, 4443-4467, https://doi.org/10.1002/2015JD024135, 2016.

Sheese, P. E., Llewellyn, E. J., Gattinger, R. L., Bourassa, A. E., Degenstein, D. A., Lloyd, N. D., and McDade, I. C.: Temperatures in the upper mesosphere and lower thermosphere from OSIRIS observations of $\mathrm{O}_{2}$ A-band emission spectra, Can. J. Phys., 88, 919-925, https://doi.org/10.1139/P10-093, 2010.

Sheese, P., McDade, I. C., Gattinger, R. L., and Llewellyn, E. J.: Atomic oxygen densities retrieved from optical spectrograph and infrared imaging system observations of $\mathrm{O}_{2}$ A-band airglow emission in the mesosphere and lower thermosphere, J. Geophys. Res., 116, D01303, https://doi.org/10.1029/2010JD014640, 2011

Siskind, D. E., Drob, D. P., Emmert, J. T., Stevens, M. H., Sheese, P. E., Llewellyn, E. J., Hervig, M. E., Niciejewski, R., and Kochenash, A. J.: Linkages between the cold summer mesopause and thermospheric zonal mean circulation, Geophys. Res. Lett., 39, L01804, https://doi.org/10.1029/2011GL050196, 2012.

Song, R., Kaufmann, M., Ungermann, J., Ern, M., Liu, G., and Riese, M.: Tomographic reconstruction of atmospheric gravity wave parameters from airglow observations, Atmos. Meas. Tech., 10, 4601-4612, https://doi.org/10.5194/amt-104601-2017, 2017.

Steck, T., Höpfner, M., von Clarmann, T., and Grabowski, U.: Tomographic retrieval of atmospheric parameters from infrared limb emission observations, Appl. Optics, 44, 3291-3301, 2005.

Taylor, M. J., Pendleton Jr., W. R., Clark, S., Takahashi, H., Gobbi, D., and Goldberg, R. A.: Image measurements of short-period gravity waves at equatorial latitudes, J. Geophys. Res., 102, 26283-26299, https://doi.org/10.1029/96JD03515, 1997.

Thomas, G. E.: Mesopheric clouds and the physics of the mesopause region, Rev. Geophys., 29, 553-575, 1991.

Thurairajah, B., Bailey, S. M., Cullens, C. Y., Hervig, M. E., and Russell III, J. M.: Gravity wave activity during recent stratospheric sudden warming events from SOFIE temperature measurements, J. Geophys. Res.-Atmos., 119, 8091-8103, https://doi.org/10.1002/2014JD021763, 2014.

Trinh, Q. T., Ern, M., Doornbos, E., Preusse, P., and Riese, M.: Satellite observations of middle atmosphere-thermosphere vertical coupling by gravity waves, Ann. Geophys., 36, 425-444, https://doi.org/10.5194/angeo-36-425-2018, 2018.

Ungermann, J., Hoffmann, L., Preusse, P., Kaufmann, M., and Riese, M.: Tomographic retrieval approach for mesoscale gravity wave observations by the PREMIER Infrared Limb-Sounder, Atmos. Meas. Tech., 3, 339-354, https://doi.org/10.5194/amt-3339-2010, 2010.

Ungermann, J., Blank, J., Lotz, J., Leppkes, K., Hoffmann, L., Guggenmoser, T., Kaufmann, M., Preusse, P., Naumann, U., and Riese, M.: A 3-D tomographic retrieval approach with advection compensation for the air-borne limb-imager GLORIA, Atmos. Meas. Tech., 4, 2509-2529, https://doi.org/10.5194/amt-4-25092011, 2011.
Vadas, S. L. and Becker, E.: Numerical modeling of the excitation, propagation, and dissipation of primary and secondary gravity waves during wintertime at McMurdo Station in the Antarctic, J. Geophys. Res., 123, 9326-9369, https://doi.org/10.1029/2017JD027974, 2018.

Vadas, S. L. and Becker, E.: Numerical modeling of the generation of tertiary gravity waves in the mesosphere and thermosphere during strong mountain wave events over the Southern Andes, J. Geophys. Res., https://doi.org/10.1029/2019JA026694, in press, 2019.

Vadas, S. L. and Liu, H.-L.: Numerical modeling of the largescale neutral and plasma responses to the body forces created by the dissipation of gravity waves from $6 \mathrm{~h}$ of deep convection in Brazil, J. Geophys. Res., 118, 2593-2617, https://doi.org/10.1002/jgra.50249, 2013.

Vadas, S. L., Fritts, D. C., and Alexander, M. J.: Mechanisms for the generation of secondary waves in wave breaking regions, J. Atmos. Sci., 60, 194-214, https://doi.org/10.1029/2004JD005574, 2003.

Vadas, S. L., Xu, S., Yue, J, Bossert, K., Becker, E., and Baumgarten, G.: Characteristics of the quiet-time hotspot gravity waves observed by GOCE over the Southern Andes on 5 July 2010, J. Geophys. Res., 124, https://doi.org/10.1029/2019JA026693, 2019.

von Savigny, C., Petelina, B. Karlsson, S. V., Llewellyn, E. J., Degenstein, D. A., Lloyd, N. D., and Burrows, J. P.: Vertical variation of NLC particle sizes retrieved from Odin/OSIRIS limb scattering observations, Geophys. Res. Lett., 32, L07806, https://doi.org/10.1029/2004GL021982, 2005.

von Savigny, C., Robert, C., Bovensmann, H., Burrows, J. P., and Schwartz, M.: Satellite observations of the quasi 5-day wave in noctilucent clouds and mesopause temperatures, Geophys. Res. Lett., 34, L24808, https://doi.org/10.1029/2007GL030987, 2007.

Wang, L. and Alexander, M. J.: Global estimates of gravity wave parameters from GPS radio occultation temperature data, J. Geophys. Res., 115, D21122, https://doi.org/10.1029/2010JD013860, 2010.

Watanabe, S., Sato, K., Kawatani, Y., and Takahashi, M.: Vertical resolution dependence of gravity wave momentum flux simulated by an atmospheric general circulation model, Geosci. Model Dev., 8, 1637-1644, https://doi.org/10.5194/gmd-8-16372015, 2015.

Witt, G.: Height, structure and displacements of noctilucent clouds, Tellus, 14, 1-18, 1962.

Wright, C. J., Hindley, N. P., Hoffmann, L., Alexander, M. J., and Mitchell, N. J.: Exploring gravity wave characteristics in 3-D using a novel S-transform technique: AIRS/Aqua measurements over the Southern Andes and Drake Passage, Atmos. Chem. Phys., 17, 8553-8575, https://doi.org/10.5194/acp17-8553-2017, 2017.

Wu, D. L., Schwartz, M. J., Waters, J. W., Limpasuvan, V., Wu, Q., and Killeen, T. L.: Mesospheric doppler wind measurements from Aura Microwave Limb Sounder (MLS), Adv. Space Res., 42, 1246-1252, https://doi.org/10.1016/j.asr.2007.06.014, 2008.

Yue, J., Miller, S. D., Hoffmann, L., and Straka III, W. C.: Stratospheric and Mesospheric concentric gravity waves over Tropical Cyclone Mahasen: joint AIRS and VIIRS satellite observations, J. Atmos. Sol.-Terr. Phy., 119, 83-90, 2014. 